\author{
FUNDAÇÃO OSWALDO ARANHA \\ CENTRO UNVERSITÁRIO DE VOLTA REDONDA \\ CURSO DE GRADUAÇÃO EM ENGENHARIA CIVIL \\ TRABALHO DE CONCLUSÃO DE CURSO
}

\author{
Carlos Eduardo Laranjeiras de Lima \\ Eduardo Gullo de Assis \\ Marcos Vinícius de O. L. Marques \\ Washington Carlos de O. S. Faria
}

\title{
ANÁLISE CONVENCIONAL E COMPUTACIONAL DOS MÉTODOS APLICADOS AO DIMENSIONAMENTO ESTRUTURAL
}

VOLTA REDONDA 


\author{
FUNDAÇÃO OSVALDO ARANHA \\ CENTRO UNVERSITÁRIO DE VOLTA REDONDA \\ CURSO DE GRADUAÇÃO EM ENGENHARIA CIVIL \\ TRABALHO DE CONCLUSÃO DE CURSO
}

\title{
ANÁLISE CONVENCIONAL E COMPUTACIONAL DOS MÉTODOS APLICADOS AO DIMENSIONAMENTO ESTRUTURAL
}

Monografia apresentada ao curso de

Engenharia Civil do UniFoa como requisito obtendo de titulo de bacharel em Engenharia Civil

Equipe:

Carlos Eduardo Laranjeiras de Lima

Eduardo Gullo de Assis

Marcos Vinícius de O. L. Marques

Washington Carlos de O. S. Faria

Orientador:

PROF. M.Sc. Sergio Luiz Taranto de Reis

VOLTA REDONDA 


\title{
FOLHA DE APROVAÇÃO
}

\author{
Alunos: \\ Carlos Eduardo Laranjeiras de Lima \\ Eduardo Gullo de Assis \\ Marcos Vinícius de Oliveira Lima Marques \\ Washington Carlos de Oliveira Silva Faria
}

\section{ANÁLISE CONVENCIONAL E COMPUTACIONAL DOS MÉTODOS APLICADOS AO DIMENSIONAMENTO ESTRUTURAL}

Banca Examinadora:

Professor Orientador

Prof. M.Sc. Sergio Luiz Taranto de Reis

Professor Avaliador

Prof. M.Sc Marcelo Estevão dos Santos

Professor Avaliador

Luigi Walter Andrighi 
Dedicamos este trabalho a todos os Engenheiros e estudantes que fazem de sua vida um eterno aprendizado. 
AGRADECIMENTO

Agradecemos a todos que contribuíram em nossa caminhada em especial nossos familiares e aos professores Sérgio Luiz Taranto de Reis e Marcelo Estevão que nos orientaram para execução deste trabalho. 


\section{RESUMO}

Será comparado o método convencional de dimensionamento de estrutura em concreto armado com o método desenvolvido pelo Software Eberick V9, visando assim relacionar as vantagens e desvantagens em ambos. Sendo assim, a linha de projeto envolverá uma única arquitetura para as duas metodologias distintas. O TCC envolverá os elementos de lajes, vigas e pilares da estrutura, levantando também as dimensões e o quantitativo de materiais utilizados. No método convencional será utilizado a técnica de cálculo à ruptura, no qual a segurança é garantida fazendo com que as solicitações correspondentes as cargas majoradas sejam menores que as solicitações últimas. Já no método via Software Eberick V9 a análise é feito por pórtico espacial. No método convencional, algumas rotinas serão automatizadas pelos Softwares Microsoft Office Excel 2013 e Ftool 3.0, porém obedecerá o roteiro manual convencional. Já no método via Software Eberick V9, a rotina é toda desenvolvida pelo Software, ficando de responsabilidade do projetista somente a entrada de dados do projeto. Sendo assim, espera-se melhor compreender a diferença de trabalhar com ambos os métodos.

Palavras-chave: estrutura; eberick V9; concreto; análise estrutural; comparação 


\section{SUMÁRIO}

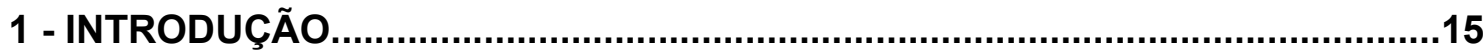

1.1 - Objetivo

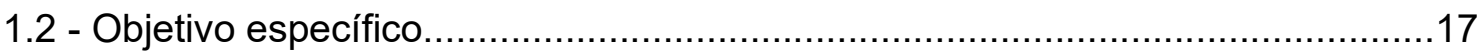

2 - CONSIDERAÇÕES TEÓRICAS ESTRUTURAIS ….......................................18

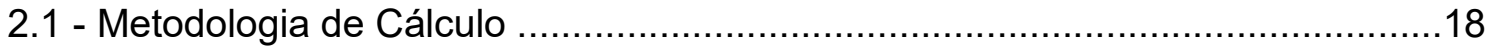

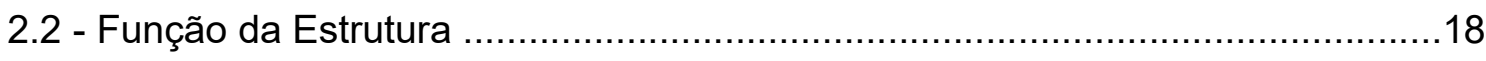

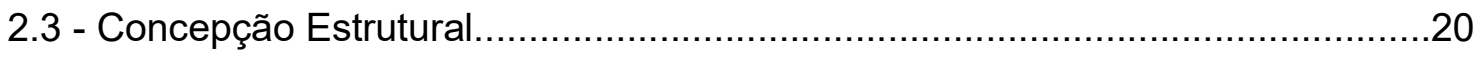

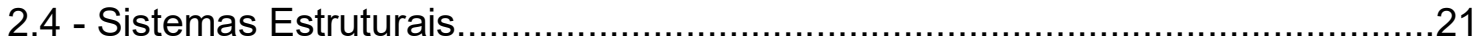

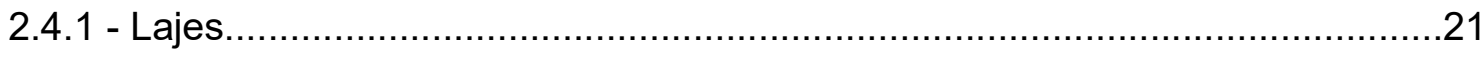

2.4.2 - Viga

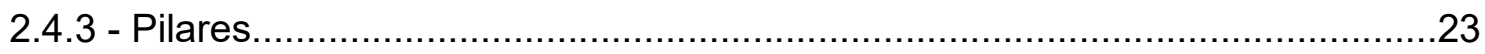

2.5 - Pavimentos e Linha de Carga seguida na Estrutura .....................................24

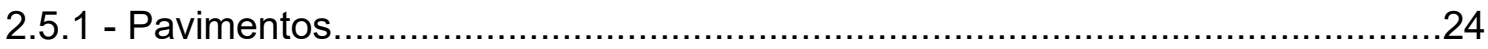

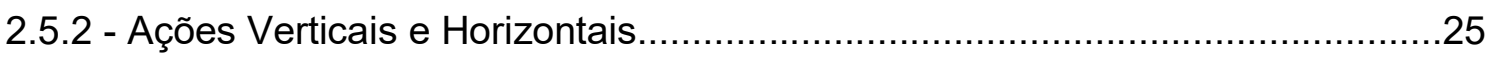

2.5.3 - Caminho das cargas nas Estruturas Convencionais.....................................26

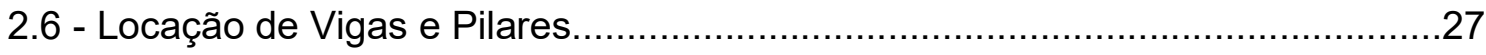

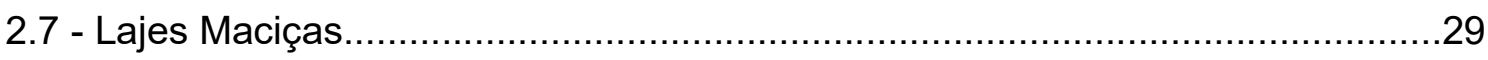

3 - COMO AS MUDANÇAS FEITAS NA NBR 6118:1978 AFETAM O

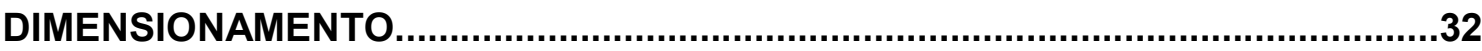

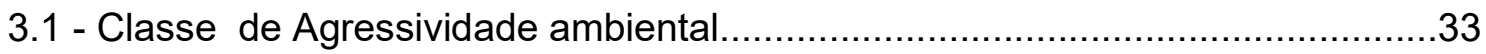

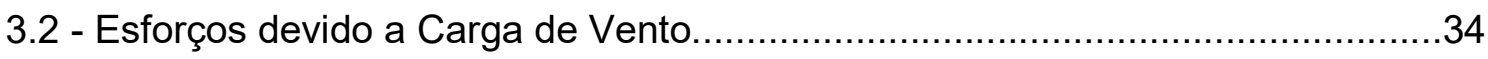

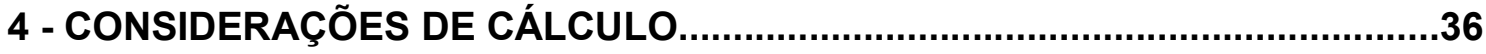


4.1 - Valores a serem considerados Método Manual de Cálculo.

4.1.1 - Estado Limite de Desempenho.....................................................

4.1.2 - Ações Permanentes e Variáveis..............................................................

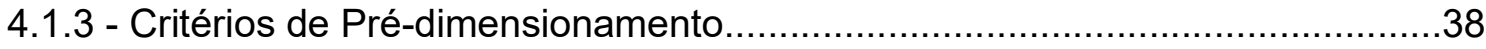

4.1.4 - Dimensionamento da Armadura das Lajes.........................................39

4.1.5 - Dimensionamento da Armadura das Vigas Flexão Simples.........................44

4.1.6 - Método de Dimensionamento das Vigas ao Cisalhamento........................46

4.1.7 - Método para Ancoragem das Armaduras...........................................47

4.1.8 - Dimensionamento de Pilares.............................................................. 50

4.2 - Considerações e critérios adotados no dimensionamento de Lajes feitas pelo

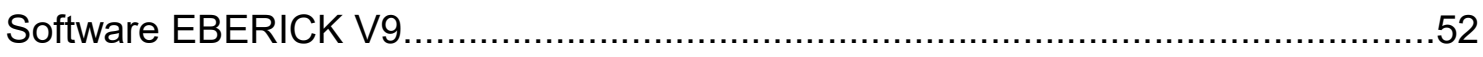

5 - ANALISE DE RESULTADOS ............................................................. 54

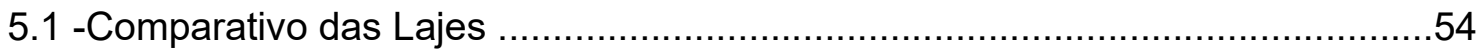

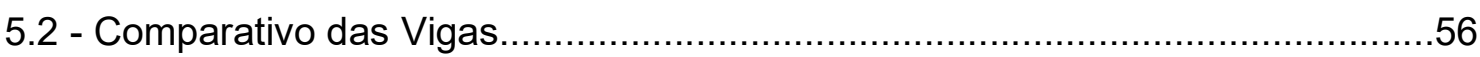

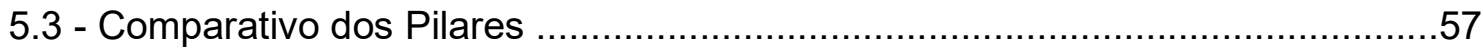

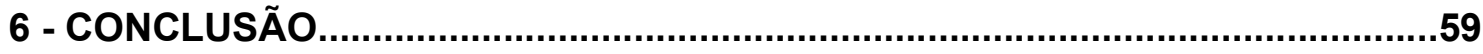

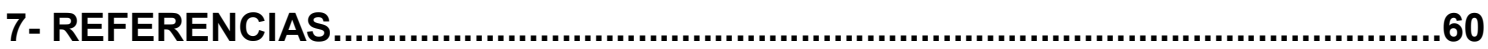




\section{LISTA DE TABELAS}

Tabela (1)- Classe de agressividades ambiental, Fonte: NBR 6118:2014, p, 17 item

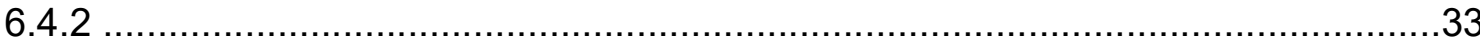

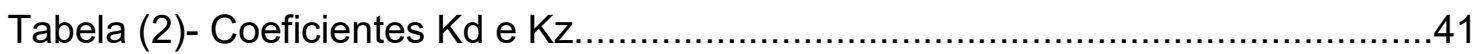




\section{LISTA DE FIGURAS}

Figura (1) - Laje Maciça, Fonte: Autores (2016).................................................23

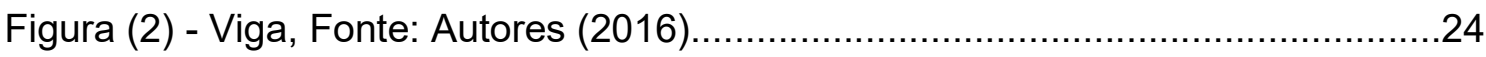

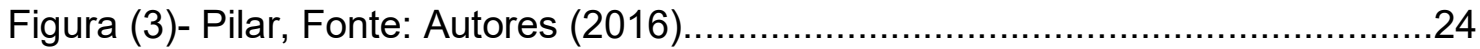

Figura (4)- Perspectiva de uma estrutura formada por lajes vigas e pilares, Fonte:

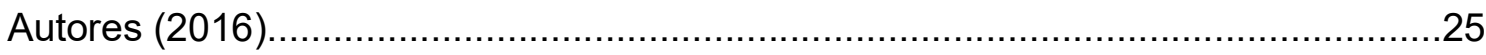

Figura (5) -Encaminhamento das ações verticais - Fonte: (DEBS, 2007)...............28

Figura (6) - Laje maciça apoiada sobre vigas, Fonte: Autores (2016).......................30

Figura(7) - Pavimento por painéis de lajes ,Fonte: Autores (2016)........................32

Figura (8) - Ferramenta de pré-dimensionamento Fonte: Autores (2016) ................40

Figura (9) - Ferramenta de dimensionamento da armadura positiva. Fonte: Autores (2016).

Figura (10) - Ferramenta de dimensionamento da armadura negativa,Fonte: Autores (2016)

Figura (11) - Domínio de estado limite ultimo de uma seção transversal (NBR 6118 / 2014)

Figura (12) - Ferramenta de dimensionamento das vigas,Fonte: Autores (2016)...50

Figura (13) - Ferramenta de dimensionamento dos pilares, Fonte: Autores (2016)..51 


\section{LISTA DE GRÁFICOS}

Gráfico (1) - Peso de Aço Armaduras Positiva da Laje, Fonte : Autores (2016)........54

Gráfico (2) - Peso de Aço Armaduras Negativa da Laje, Fonte: Autores (2016).......54

Gráfico (3) - Comparação Total das Armaduras das Lajes, Fonte: Autores (2016)...55

Gráfico (4) - Comparação Total de Concreto das Lajes, Fonte: Autores (2016).......55

Gráfico (5) - Comparação Total das Armaduras de Vigas, Fonte: Autores(2016).....56

Gráfico (6) - Comparação Total de Concreto das Vigas, Fonte: Autores (2016).......57

Gráfico (7) - Comparação Total das Armaduras dos Pilares, Fonte: Autores(2016)..58

Gráfico (8) - Gráfico (8) - Comparação Total de Concreto dos Pilares, Fonte: Autores (2016). 


\section{LISTA DE ABREVIATURAS}

ABNT -Associação Brasileira de Normas Técnicas

Ac - Área de concreto

As - Área de Aço

As calculado - área de seção de cálculo

As efetivo - Área efetiva ( adotada )

ase - área de estribo

Asmax - Área máxima de aço

Asmin - Área mínima de aço

bw - Base seção transversal de lajes e vigas

CAA - Classe de Agressividade Ambiental

ELS - Estado Limite de Serviço

ELU - Estado Limite Ultimo

$\mathcal{E}$ - Deformação

Es - Deformação do aço

Esyd - Deformação de cálculo do aço

fbd- Resistência de aderência

fcd - Tensão de compressão de cálculo

fck - Tensão de compressão característica

fctkinf - Resistência característica a tração inferior

fctm - Resistênciamédia a tração do concreto

fk - Resistência dos característica 
fk,inf - Resistência característica inferior

fk,sup - Resistência característica superior

fm - Resistência media

fyd - Tensão de tração de cálculo de aço

fyk - Resistência característica ao escoamento do aço

Kd - Parcela referente a altura útil

Kg - Quilograma

Km - Parcela referente ao momento último

Ky - Posição do eixo neutro

Kz - Parcela referente ao braço de alavanca

lb - Comprimento de ancoragem básica

ebmin-Comprimentodeancoragem mínima

ebnec- Comprimento de ancoragem necessária

Ix - Menor dimensão da laje

ly - Maior dimensão da laje

$\mathbf{m}^{2}$ - Metro quadrado

$\mathbf{m}^{3}$ - Metro cúbico

Md - Momento de cálculo

MPa -Mega Pascoal

$\eta$-coeficiente de aderência, entre aço e concreto;

n1 - para aço liso, entalhado ou nervurado;

n2 - em situações de boa ou má aderência;

n3 - relacionado com diâmetro da barra. 
P - Número de pernas do estribo

p - porcentagem de armadura

Rst - Resultante das tensões de tração do aço

Rst - Resultante de tensões de tração do aço

S- Espaçamento da armadura

Vc - Parcela de cortante absorvida pelo concreto

Vrd2 - Força cortante resistente de cálculo do concreto

Vsd - Cortante de cálculo

Vsw - Armadura transversal 


\section{LISTA DE ANEXOS}

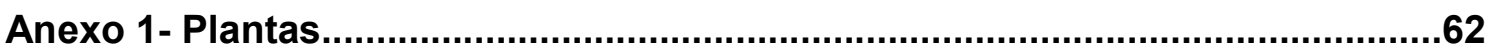

Anexo 1.1 - Planta de Arquitetura....................................................63

Anexo 1.2 - Corte Esquemático do Projeto.........................................64

Anexo 2 - Planta de Formas(Eberick V9)........................................................65

Anexo 3 - Planta de Formas ( Método convencional ).....................................67 


\section{INTRODUÇÃO}

A análise de edifícios é um tópico de grande importância para a Engenharia de Estruturas. Qualquer desenvolvimento técnico obtido para essa área produz, por efeito de escala, um benefício sensível para toda a sociedade, porque os edifícios são em número tão expressivo que deixam as outras estruturas em situação de menor destaque (LISERRE, 2003,p33).

Até o advento dos microcomputadores PC em 1981, os projetos dos edifícios de Concreto Armado eram feitos com muito trabalho manual. Os cálculos eram tantos que o engenheiro de estruturas era conhecido como "Engenheiro Calculista" (LONGO, 2003).

A análise da estrutura de um edifício consistia, basicamente em subdividir a estrutura em elementos isolados e simples, onde separava-se as lajes, vigas e os pilares no qual as lajes são apoiadas nas vigas, que por sua vez descarregavam sobre os pilares as cargas, dar-se assim o nome de pavimento. No caso da carga de vento, a analise se torna muito difícil e trabalhosa, na maioria das vezes sendo desprezados seus efeitos que afetariam os projetos estruturais, sobretudo os edifícios de até dez pavimentos formados por estrutura convencional (lajes maciças, vigas e pilares). Quando não era indicado ignorar o vento, a estrutura de contraventamento era formada em sua base por pórticos planos. Com o avanço e evolução da Norma, e todas reações diversificadas a serem consideradas torna-se quase inviável levar-se as considerações no geral para que se possa executar o dimensionamento em cálculo estrutural feito manualmente.

O avanço da tecnologia e a introdução dos computadores abriu a possibilidade de uma verificação e análise mais precisa e atual da estrutura, levando assim uma análise de forma mais homogênea da estrutura. Assim o modo de análise da estrutura começou a ficar mais próximo da realidade possível tornando-se mais seguros e precisos. Em relação a carga devido ao vento reagindo na estrutura é possível calcular seus esforços e os deslocamentos da estrutura como um todo.

Hoje o auxílio de um computador tornou-se indispensável para projetos de edifícios ou seja auxiliando nos cálculos ou efetuando o detalhamento dos elementos estruturais do projeto. Cada vez mais a estrutura é analisada como um 
todo, considerando elementos variáveis diversos como a temperatura, solo e vento. E no caminho evolutivo da tecnologia, os programas computacionais voltados ao cálculo de estruturas em concreto armado e a NBR 6118/2014, vêm acrescentando verificaçõesminuciosas tanto em análise quanto no dimensionamento, pode-se presumir que juntamente com a tecnologia, a norma segue esse avançoo que antes era inviável, agora é possível que seja feita essas análises diversas na estrutura.

Os softwares que estão no mercado auxiliam ao engenheiro a desviar de alguns problemas sobre tudo a ausência de tempo e facilitar os cálculos que seriam extremamente cansativo e demorado para que todas as considerações da norma atual que são impostas para os fins de dimensionamento apresentados, fossem efetuados pela forma manual.

O surgimento do software Eberick, quando a empresa ALTOQI Tecnologia em informática Itda, lança a linha PRO, através dos produtos PROVIGA, PROLAJE, PROPILAR e PROINFRA desenvolvida para ambiente MS-DOS, a analise dos elementos estruturais eram feitas separadamente ou seja de maneira isolada. Em 1996, o Eberické lançado. Este Software tem como objetivo a elaboração de projeto estrutural em concreto armado, realizando o dimensionamento lajes, vigas, pilares e fundações, levando em consideração as especificações normativas da NBR 6118.

\section{1 - Objetivo}

Este trabalho tem como seu principal objetivo apresentar os conceitos de dois diferentes métodos de análise de uma estrutura, o método tradicional de cálculo seguindo a norma NBR 6118:1978 que seguia a verificação dos elementos isoladamente e o por pórtico espacial tendo como ferramenta o software de cálculo estrutural em concreto armado Eberick V9, que segue a norma atual de NBR 6118:2014 com suas devidas indicações e atualizações. 


\section{2 - Objetivo específico}

Mostrar suas particularidades, limitações e suas principais diferenças obtidas fazendo assim uma comparação dos esforços, quantitativos de materiais, tempo de trabalho e modelo estático dos elementos. Essa comparação será feita de toda a estrutura ( Lajesmaciças, vigas e pilares ), visando assim relacionar as vantagens e desvantagens de ambos os métodos, de acordo com a NBR 6118:1978 que será utilizada no método tradicional de cálculo que adota coeficientes de segurança para que sejam realizados os cálculos e a NBR 6118:2014 a norma mais atual que o EBERICK V9 leva em consideração para que seja realizado os cálculos pelo programa. 


\section{2 - CONSIDERAÇÕES TEÓRICAS ESTRUTURAIS}

O estudo será feito com base em uma única arquitetura predial em ambos os métodos.

\section{1 - Metodologia de Cálculo}

No método convencional, algumas rotinas serão automatizadas com o uso de Softwares como Microsoft Office Excel 2013 e Ftool 3.0, porém obedecerá o roteiro manual convencional.

O Eberick é um programa comercial para projeto estrutural em concreto armado, que engloba as etapas de lançamento e análise da estrutura, dimensionamento e detalhamento dos elementos, de acordo com a NBR 6118:2014.

\section{2 - Função da Estrutura}

"Estrutura é tudo aquilo que sustenta, tal qual o esqueleto humano.

No entanto, o conceito de estrutura é mais amplo e encontra-se em todas as áreas do conhecimento humano" (REBELLO, 2001, p.21).

Para suportar as cargas verticais transmitidas a um plano horizontal (piso de um edifício), empregando-se como material o concreto armado, executa-se uma placa deste material monolítico, a qual tem denominação de laje. Com as lajes não devem ter espessura superior a um limite imposto pela pratica, por isso, colocam-se peças de maior altura, em geral disponível em duas direções perpendiculares, que vão servir de apoio ás lajes e se denominam vigas,as lajes repousando em um conjunto de vigas formam a estrutura de cada pavimento.Para transmitir as cargas de cada pavimento ao solo, dispõem-se de apoios verticais denominado pilares (ROCHA 1989)

A estrutura é o conjunto formado basicamente pelos elementos chamados por lajes, vigas e pilares, sua função é de principalmente manter o edifício estável e seguro durante toda a sua construção e uso. Tem também a função de atender as formas mais variadas de arquiteturas. 
É muito importante que o projeto deestrutura seja levada em consideração em conjunto com a arquitetura pois dessa relação serão adotados os critérios que toda construção deve seguir.

O projeto arquitetônico representa, de fato, a base para a elaboração do projeto estrutural. Este deve prever o posicionamento dos elementos de forma a respeitar a distribuição dos diferentes ambientes nos diversos pavimentos. Mas não se deve esquecer de que a estrutura deve também ser coerente com as características do solo no qual ela se apóia. (PINHEIRO, 2007, p s/n).

O projetista se possível deve sair do escritório e visitar o local que a construção será imposta para ter uma noção abrangente das condições que irá encontrar em seu projeto, a idéia geral é que o projetista levante o máximo de dados possível para o auxílio e elaboração de seu projeto. Conceitos importantes como solo, condição do tempo topografia do terreno e localização da obra e sua finalidade são de extrema importância para que não haja imprevistos no projeto.

Uma vez definida a localização dos pilares, vigas e lajes, parte-se para o pré- dimensionamento dos elementos estruturais. Nesta etapa, o engenheiro de estruturas precisa ter certo conhecimento do comportamento estrutural para determinar as dimensões dos elementos de maneira a obter um menor custo para a obra e respeitar prescrições feitas pela Norma. As dimensões dos elementos variam com as cargas, vãos, materiais, tipo estrutural, etc. (SOARES e DEBS, 1999).

LOURENÇO (1992) apresenta a seguinte subdivisão do projeto global de edifícios de concreto armado:

Concepção: Omais importante. Uma boa experiência prática do projetista obriga a uma visão global que forneça o suporte para as fases seguintes.

Dimensionamento: Significa definir as dimensões e armaduras da estrutura. Nessa etapa o projetista efetua os cálculos utilizando um método de dimensionamento e seguindo as exigências impostas pela NBR 6118.

Validação: É para verificar os passos anteriores executando uma verificação final e completa das etapas que a antecedem. Confirmando assim o que tinha sido dimensionado. 


\title{
2.3 - Concepção Estrutural
}

\begin{abstract}
"Conceber uma estrutura é ter consciência dapossibilidade da sua existência; é perceber a sua relação com o espaço gerado; é perceber osistema ou sistemas capazes de transmitir as cargas ao solo, da forma mais natural, éidentificar os materiais que, de maneira mais adequada, se adaptam a esses sistemas". (REBELLO, 2001,p.26),
\end{abstract}

A criação da estrutura de um edifício emprega umarranjo ou combinação adequada dos elementos estruturais existentes e também define as ações a considerar, tendo o objetivo de atender a todos os requisitos de segurança, durabilidade, estética, funcionalidade, entre outros, que as construções devem conter.

Segundo ( Barboza, 2008 ), a elaboração da estrutura de um edifício algumas diretrizes são importantes, exemplo:

- A estrutura deve atender tanto quanto for possível a forma, a estética, seguindo ao máximo as condições apresentadas pelo projeto arquitetônico;

- Seus elementos estruturais devem ser embutidos nas paredes de alvenaria de vedação, geralmente são as vigas e os pilares.

- A funcionalidade dos elementos estruturais devem-ser levados em consideração na hora de sua locação na estrutura.

- As cargas devem ser transmitidas mais diretamente possível tendo um caminho mais curto, evitando criar apoios indiretos em outras vigas importantes também evitando locar pilares sobre vigas ( viga de transição ).

- As dimensões da estrutura colocadas em planta devem ter limites de geralmente de 30m no máximo, visando assim amenizar os efeitos de retração devido principalmente pelo efeito da variação da temperatura. Isso pode ser obtido pela especificação de juntas de separação (também chamadas juntas de dilatação), que resultam em blocos de estruturas independentes, que não interagem entre si;

- Em edifícios de múltiplos pavimentos a verificação da estabilidade global da estrutura assume grande importância, porque a ação horizontal do vento alcança valores significativos. A especificação da 
seção transversal das vigas, e principalmente dos pilares, deve ser feita de maneira muito criteriosa e a estrutura de contraventamento deve ser avaliada cuidadosamente;

- Em edifícios com garagens a posição dos pilares devem levar em consideração o trânsito dos veículos tão como o posicionamento e o espaçamento das vagas ali dispostas, para facilitar o fluxo.

\section{4 - Sistemas Estruturais}

Os arranjos estruturais (sistemas estruturais) podem ser compostos apenas por um tipo de elemento estrutural, ou formando um conjunto destes elementos que é o mais certo de acontecer nas construções.

Os elementos que usualmente compõem as estruturas são as lajes, as vigas e os pilares. A seguir apresenta-se uma breve descrição de cada elemento, apresentada em BASTOS ${ }^{2}$ (2006).

\subsection{1 - Lajes}

As lajes são os elementos planos que se destinam a receber a maior parte das ações aplicadas numa construção, como de pessoas, móveis, pisos, paredes, e os mais variados tipos de carga que podem existir em função da necessidade arquitetônica do espaço físico que a laje faz parte. As ações são comumente perpendiculares ao plano da laje (Figura 1), podendo ser divididas em: distribuídas na área (peso próprio, revestimento de piso, etc.), distribuídas linearmente (paredes) ou forças concentradas. As ações são geralmente transmitidas para as vigas de apoio nas bordas da laje, mas ocasionalmente também podem ser transmitidas diretamente aos pilares; 

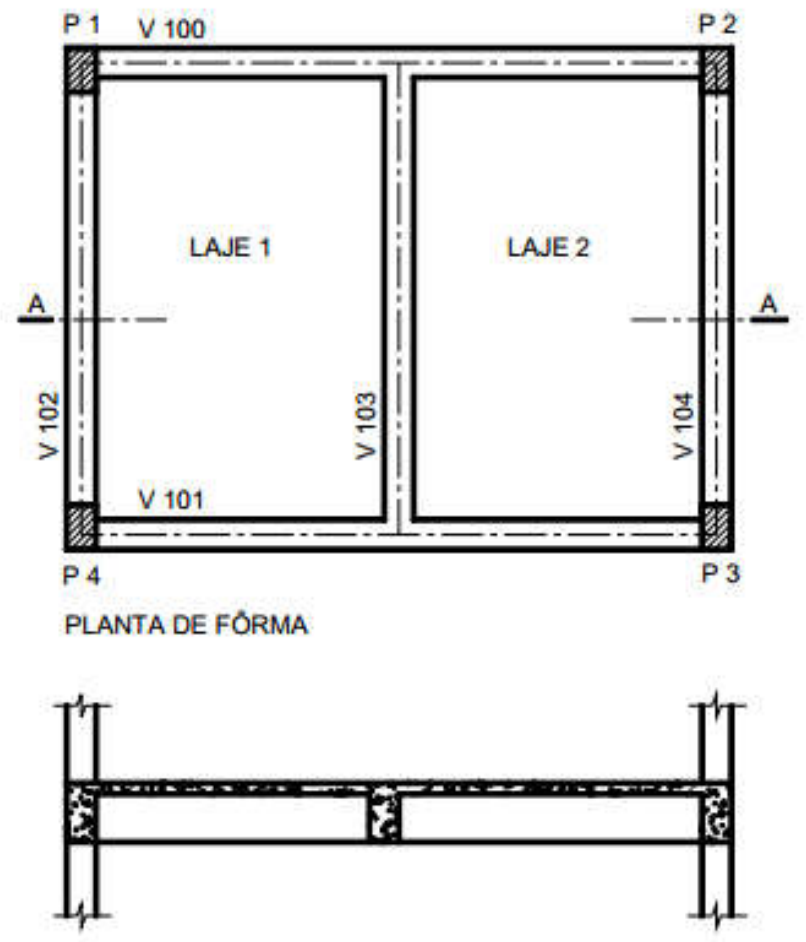

CORTE A

Figura(1) - Laje Maciça, Fonte: Autores (2016)

\subsection{2 - Viga}

Pela definição da NBR 6118/03 (item 14.4.1.1), vigas "são elementos linearesem que a flexão é preponderante". As vigas são classificadas como barras e são normalmente retas e horizontais, destinadas a receber ações das lajes, carga de alvenaria e carga de outras vigas. A função das vigas é basicamente vencer vãos e transmitir as ações nelas atuantes para os apoios, geralmente os pilares. As ações são geralmente perpendicularmente ao seu eixo longitudinal, podendo ser concentradas ou distribuídas. Podem ainda receber forças normais de compressão ou de tração, na direção do eixo longitudinal. As vigas, assim como as lajes e os pilares, também fazem parte da estrutura de contraventamento responsável por proporcionar a estabilidade global dos edifícios às ações verticais e horizontais; 


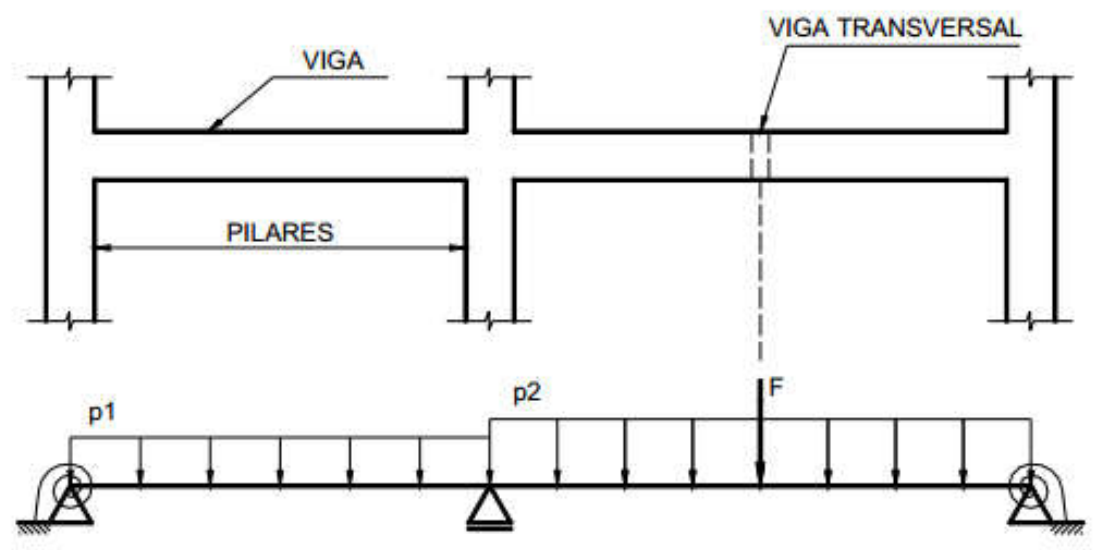

Figura (2) - Viga, Fonte: Autores (2016).

\subsection{3 - Pilares}

Pilares são "elementos lineares de eixo reto, usualmente dispostos na vertical,em que as forças normais de compressão são preponderantes" (NBR 6118/03, item 14.4.1.2). Sua função é transmitir os esforços transmitidos à ele em direção a fundação do edifício podendo também transmitir para outros apoios, estas cargas são geralmente transmitidas para os pilares através das vigas que recebem cargas das lajes e da alvenaria, conforme Figura (3).

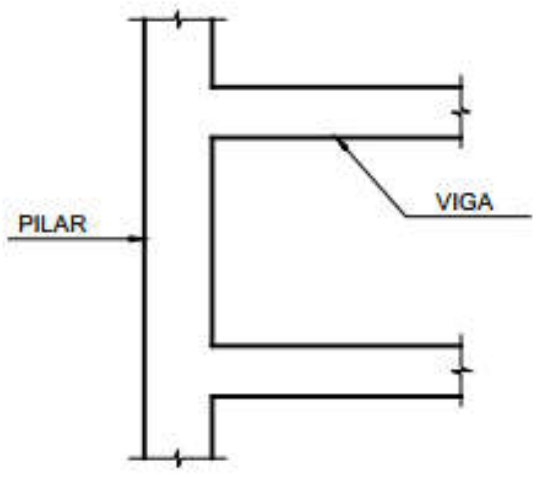

Figura (3) Pilar, Fonte: Autores( 2016 ). 


\subsection{Pavimentos e Linha de Carga da Estrutura}

\subsection{1 - Pavimentos}

A Figura 4 exemplifica uma estrutura formada pelos elementos.

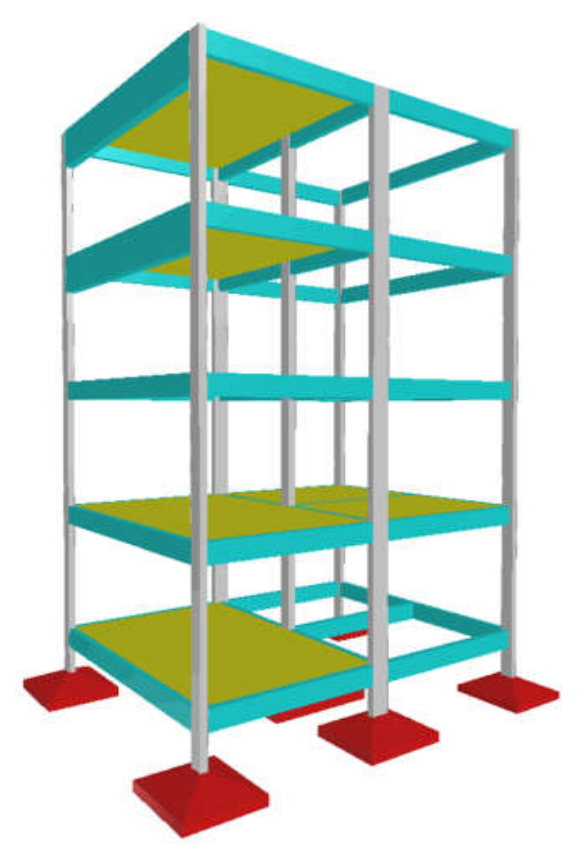

Figura (4)- perspectiva de uma estrutura formada por lajes vigas e pilares, Fonte: Autores (2016).

O esquema estrutural pode ser analisado segundo dois planos, o vertical e o horizontal que seria o piso, o primeiro citado éindispensável para sustentar a estabilidade global do edifício.

Quando as lajes se unem as vigas formam então os pavimentos, que é responsável a receber as ações mais importantes dos edifícios, sendo as ações de 
uso do edifício. Juntamente com as vigas e lajes formando a estrutura de contraventamento, e garantir assim a estabilidade global da estrutura.

Este sistema estrutural que é formado deve atender a um equilíbrio e ter resistência necessários, tanto quanto para as ações verticais e também para as horizontais eles sendo aplicadas juntamente ou não.

Para uma melhor solução estrutural é imprescindível conhecer todos os critérios que a construção tende a atender, tal como: as cargas atuantes, desígnio da obra, complexidade de construção, economia, rapidez de execução, materiais mais comuns na região, existência de mão de obra especializada, dentre outros. É necessário que uma hierarquia ou a prioridade dos requisitos que virão a aparecer. A estrutura melhor planejada irá ser aquela que seguiros requisitos existentes de uma forma mais eficaz segundo a hierarquia de importância as quais foram submetidas inicialmente. Segundo REBELLO (2001), a pior solução é a que apresenta os maiores desencontros entre os objetivos dos projetos arquitetônico e estrutural.

\footnotetext{
"Os pavimentos são estruturas de superfície plana compostos de um ou maiselementos. Esses elementos são usualmente chamadas de lajes, principalmente se executadascom concreto armado ou protendido. Sob o ponto de vista estrutural são placas de concreto,com ações preponderantemente perpendiculares ao seu plano médio, em que a dimensãoperpendicular à superfície, usualmente chamada espessura, é relativamente pequena frenteàs demais (largura e comprimento)." (FIGUEIREDO FILHO e CARVALHO, 2004).
}

No piso de um edifício é onde as variações maiores de tipo de sistema estrutural ocorrem com maiores âmbito. As lajes, vigas e pilares de forma geral formam um pavimento do edifício, também em lajes que apoiam-se diretamente nos pilares. Todas elas apresentam características próprias, pois existem variações de lajes ( nervurada, maciça, protendida, pré-moldada e moldada in loco ) assim como as vigas ( armada, protendida, etc ), essas características devem ser analisadas assim que combinadas. 


\subsection{2 - Ações Verticais e Horizontais.}

As duas ações existentes são as verticais e horizontais, ambas devem percorrer um caminho da estrutura até chegar a sua fundação e repousar ao sol.

Ações verticais- geralmente são formadas, por pessoas, móveis e equipamentos diversos, tal como o próprio peso dos elementos que fazem parte da construção e ações das forças gravitacionais,

Ações Horizontais - estas ações são formadas basicamente por duas fontes de carga que atuam na estrutura, o vento e o desaprumo global, o vento forma a "; carga de vento " e o desaprumo global constitui-se em uma imperfeição geométrica o qual a estrutura se inclina em uma direção( não se pode aceitar recalque diferencial na fundação ).

\subsection{3 - Caminhos das cargas nas estruturas convencionais}

"Diversos métodos de cálculo estrutural e processos executivos foram desenvolvidosnas últimas décadas, mas apesar disso o que prevalece no mercado de edifícios residenciais,por efeito cultural, são estruturas formadas por vigas e lajes" (CALDURO e LEME, s/d).

Estrutura convencional, é formada por lajes que se apoiam nas vigas que por sua vez apoia-se nos pilares, descarregando assim todos os esforços na fundação.

As cargas geralmente aplicadas nas lajes percorrem até suas bordas e encontram-se com as vigas de apoio possivelmente locadas em suas bordas. As vigas transmitem essas ações diretas aos pilares que por sua vez transmitem as cargas verticalmente até a fundação (Figura 5). 


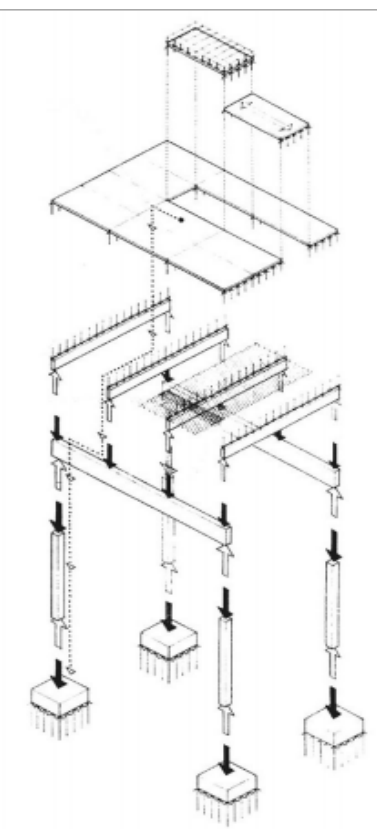

Figura (5) -Encaminhamento das ações verticais - Fonte: ( DEBS, 2007 )

As paredes nesse sistema são simplesmente para fins de vedação e são denominadas " paredes de vedação " .

\section{6 - Locação de Vigas e Pilares}

Entende-se como "lançamento de vigas e pilares" o procedimento de locar, sobre aarquitetura, as vigas e pilares resultantes da concepção estrutural adotada (REBELLO, 2001).

SOARES e DEBS (1999) acrescentam que existe um número considerável de variáveis para locação do posicionamento dos elementos estruturais, acima de todos os pilares. Fora além de levar em consideração as características dos materiais, geometrias e ações diversas externas, podendo também variar em função do solo, sua forma de execução o processo de construção, preço de material e mão de obra, dentre outros. Vinculam ainda que arquitetura limitam muito o projeto estrutural, sendo extremamente difícil a harmonização dos projetos, porém, o projeto estrutural deve atender integralmente o projeto arquitetônico. Essa dificuldade fica visível no dimensionamento, pois é feito exclusivamente pelo engenheiro devido sua 
experiência sem nenhum auxílio de computador. Segundo ALBUQUERQUE (1999), o lançamento da estrutura segue alguns critérios. "Geralmente se inicia pela locação dos pilares no pavimento-tipo,que segue a seguinteordem: pilares de canto, pilares nas áreas comuns a todos os pavimentos (região da escada edos elevadores), pilares de extremidade (situados no contorno do pavimento) e finalmentepilares internos”. E complementa “... a colocação das vigas vai depender do tipo de laje queserá adotada, já que as vigas delimitam o contorno das lajes. Devem-se colocar as vigas noalinhamento das alvenarias e começar definindo as vigas externas do pavimento. Alémdaquelas que ligam os pilares que constituem os pórticos, outras vigas podem sernecessárias, para dividir um painel de laje com grandes dimensões. Com o posicionamento das vigas as lajes ficam praticamente definidas, faltando apenas, caso existam, as lajes em balanço".

As vigas devem ser lançadas levando-se em consideração os três principais aspectos: vãos das lajes, encaixe da viga nas paredes de vedação e a configuração da estrutura para resistência à ação horizontal do vento.

É altamente desejável que as vigas fiquem imperceptíveis o mais possível no edifício acabado, o que se consegue lançando as vigas no traçado das paredes, para que nelas fiquem embutidas.

O arranjo ou posicionamento das vigas e pilares podem ser feito simultaneamente, pois a posição de um influencia a posição do outro. Como uma regra geral deve-se procurar o arranjo estrutural que leve ao menor trajeto possível para as cargas, dos seus pontos de aplicação até os apoios (pilares).

Nem sempre é possível o posicionamento de pilares em todos os cruzamentos das vigas, o que seria desejável.

O delineamento do arranjo estrutural pode ser também iniciado pelo posicionamento das vigas do piso. As lajes e os vãos surgem em consequência do posicionamento das vigas. A situação ideal seria a de se obter esforços máximos iguais na maioria das lajes, o que é raramente possível.

No caso dos vãos das vigas também seria desejável obter um equilíbrio entre os esforços solicitantes máximos, o que de modo geral não é possível alcançar, em função das mais diversas disposições das paredes, ou do projeto arquitetônico. 


\section{7 - Lajes Maciças}

“Lajes maciças são aquelas onde toda a espessura é composta por concreto, contendoarmaduras longitudinais de flexão e eventualmente armaduras transversais, e apoiadas emvigas ou paredes ao longo das bordas. Lajes com bordas livres são casos particulares daslajes apoiadas nas bordas" (BASTOS, 2005).

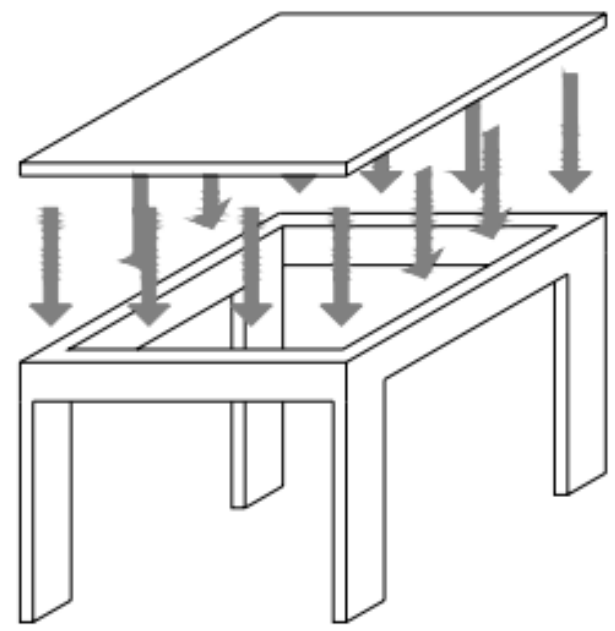

Figura (6) - laje maciça apoiada sobre vigas, Fonte: Autores( 2016 )

Nos pavimentos dos edifícios as lajes maciças são usadas com mais frequência que outros tipos de lajes.A Teoria das Placas com apoio a Teoria da Elasticidade,essas teorias fornece ao engenheiro a possibilidade de executar 0 dimensionamento sem auxílio de computadores. Devido a seu meio pratico de dimensionamento fez este tipo de laje ser de mais uso perante as construtoras.

Alguns autores descrevem esse método de dimensionamento como, MONTOYA (1973) BASTOS (2005) e GIONGO (2007) e vários outros.

As lajes correspondem a $50 \%$ do total de concreto consumido na edificação. Elas são o modelo de lajes que apresentam maior consumo de concreto, sendo a espessura a dimensão mais importante a ser quantificada.(SOARES e DEBS,1999). 
As lajes são em geral bidimensionais, sua espessura é extremamente menor que as duas outras dimensões, a espessura da laje é diretamente ligada ao consumo de concreto. Podendo na prática a variação desta espessura varia de 7 à $16 \mathrm{~cm}$ tornando-se inviável uma espessura maior pois o seu próprio peso causaria deformações.

Segundo NBR 6118/2014 sobre espessura de lajes maciças diz:

a) $7 \mathrm{~cm}$ para cobertura não em balanço;

b) $8 \mathrm{~cm}$ para lajes de piso não em balanço;

c) $10 \mathrm{~cm}$ para lajes em balanço;

d) $10 \mathrm{~cm}$ para lajes que suportem veículos de peso total menor ou igual a 30 $\mathrm{kN}$;

e) $12 \mathrm{~cm}$ para lajes que suportem veículos de peso maior que $30 \mathrm{kN}$;

f) $15 \mathrm{~cm}$ para lajes com protensão apoiadas em vigas, com o mínimo de $\frac{\ell}{42}$ para lajes de piso biapoiadas e $\frac{\ell}{50}$ para lajes de piso contínuas;

g) $16 \mathrm{~cm}$ para lajes lisas e $14 \mathrm{~cm}$ para lajes-cogumelo, fora do capitel

Adotando pequenas espessuras para as lajes maciças alguns problemas serão notados. O isolamento acústico e térmico não são bons, tendendo-se assim adotar revestimentos que os isolem.

Em grande maioria os vãos máximos adotados por engenheiros em relação a lajes são de 3.5 a 6 m. Pois aumentando o vão a espessura da laje se torna cada vez maior aumentando assim o consumo de concreto nela imposta. Quando as lajes ultrapassam essas dimensões o engenheiro usa vigas intermediárias para reduzir suas dimensões o pavimento passa a ter os chamados painéis de lajes como indicado pela (Figura 7). Estes apoios na realidades não são fixos porém para uma simplificação de cálculo é considerado são considerados fixos ou seja sem deslocamento vertical. Esses painéis na execução são concretados juntos. Essa situação de painéis de lajes servem somente para facilitar seu dimensionamento. 


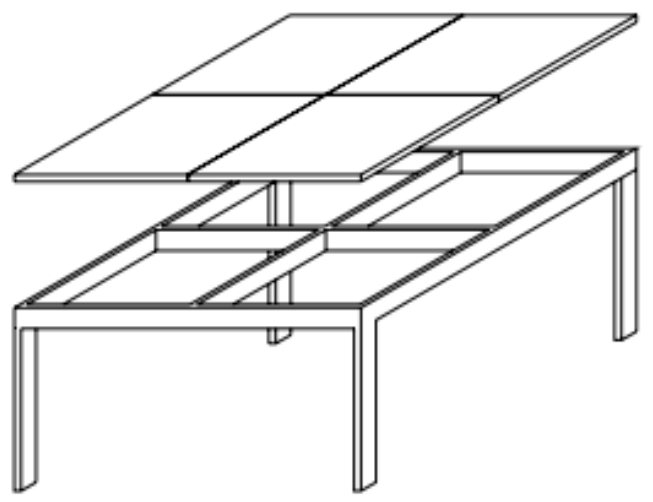

Figura(7). - Pavimento por painéis de lajes ,Fonte: Autores ( 2016 )

A maior existência de vigas torna a obra mais cara pois tem um aumento no concreto significativo e no número de formas em recortes, porem a quanto maior número de vigas, aumenta a rigidez e faz a carga percorrer um caminho mais curto até o solo, dando a possibilidade de dimensionamento de elementos de menor dimensão. 


\section{COMO AS MUDANÇAS FEITAS NA NBR 6118:78 AFETAMO DIMENSIONAMENTO.}

Este trabalho tem muito haver com as mudanças desta norma ao longo dos anos, o foco é determinar as maiores mudanças que resulta na inviabilidade de que o cálculo possa continuar sendo feito somente pelo método manual sem ajuda de software.

Uma mudança importante na NBR 6118 em sua primeira versão a atual, é que a de 78 , tratava de dimensionamento e execução do projeto, hoje a execução fica por conta da NBR14931/2003, sendo cada assunto exclusivamente abordado pela norma específica voltada a ele.

A NBR 6118/1978 passou por transformações técnicas em relação ao conhecimento quanto aos instrumentos disponíveis, sobretudo com advento computacional. A disponibilidade de ferramentas computacionais mais eficientes deu-se possível um número maior de verificações e com maior refinamento e de forma mais simples. Neste período também houve, uma preocupação maior sobre a vida útil de uma estrutura, deste modo a NBR 6118 teve que sofrer alterações visando atender aos novos avanços na tecnologia e também atender esses novos critérios de durabilidade da estrutura.

As alterações na NBR 6118 podem ser combinados em três etapas do projeto, como segue: definição de critérios de qualidade e durabilidade, análise estrutural e dimensionamento. As etapas são imprescindivelmente interligadas entre si, dependendo uma sempre da outra.

As recomendações para os requisitos de qualidade e durabilidade constituem uma das principais mudanças da atual norma, aqui são apresentados e definidos os critérios mínimos esperados para uma estrutura em concreto armado: capacidade resistente, desempenho em serviço e durabilidade. O primeiro é referente à segurança à ruptura; o segundo é referente a integridade da estrutura e o terceiro é referente a conservação da estrutura ao longo do tempo. 
Em linha com esta nova visão, a nova recomendação da NBR 6118, mais abrangente, procura conceber a estrutura como um todo, num formato mais próximo da realidade, no qual existem interações de diversos componentes, dando ênfase a todas as etapas do projeto (Instituto brasileiro do concreto, 2007 p.18)

\section{1 -Classe de Agressão Ambiental - ( CAA )}

As normas se diferenciam também em relação a Classe de Agressão Ambiental (CAA), é direcionado as ações químicas e físicas da estrutura, existem classes que as estruturas devem se enquadrar de acordo com agressividade que é submetida, especificando assim a resistência mínima que o concreto deve ter, assim como o cobrimento mínimo da armadura e máxima abertura de fissura, no Brasil não era usado estas medidas enquanto pelo mundo já existiam essas especificações normativas em muitos países.

A tabela mostra as classes de agressividades ambiental.

\begin{tabular}{|c|c|c|c|c|}
\hline \multirow{2}{*}{\multicolumn{2}{|c|}{$\begin{array}{c}\text { Classe de } \\
\text { agressividade } \\
\text { ambiental }\end{array}$}} & Agressividade & \multirow{2}{*}{$\begin{array}{l}\text { Classificação geral do tipo de } \\
\text { ambiente para efeito de projeto }\end{array}$} & \multirow{2}{*}{$\begin{array}{c}\text { Risco de } \\
\text { deterioração da } \\
\text { estrutura }\end{array}$} \\
\hline & & \multirow[b]{2}{*}{ Fraca } & & \\
\hline & I & & $\begin{array}{c}\text { Rural } \\
\text { Submersa }\end{array}$ & Insignificante \\
\hline & II & Moderada & Urbana a, b & Pequeno \\
\hline & III & Forte & $\begin{array}{l}\text { Marinha a } \\
\text { Industrial a. b }\end{array}$ & Grande \\
\hline & IV & Muito Forte & $\begin{array}{c}\text { Industrial a.c } \\
\text { Respingos de maré }\end{array}$ & Elevado \\
\hline 日 & \multirow{3}{*}{\multicolumn{4}{|c|}{$\begin{array}{l}\text { Pode-se admitir um microclima com uma classe de agressividade mais branda (uma classe acima) para } \\
\text { ambientes internos secos (salas, dormitórios, banheiros, cozinhas e áreas de serviços de apartamentos } \\
\text { residenciais e conjuntos comerciais ou ambientes com concreto revestido com argamassa e pintura). } \\
\text { Pode-se admitiruma classe de agressividade mais branda (uma classe acima) em obras em regiôes } \\
\text { de clima seco, com umidade média relativa do ar menor ou igual a } 65 \% \text {, partes da estrutura protegidas } \\
\text { de chuva em ambientes predominantemente secos ou regiões onde raramente chove. } \\
\text { Ambientes quimicamente agressivos, tanques industriais, galvanoplastia, branqueamento em indús- } \\
\text { trias de celulose e papel, armazéns de fertilizantes, indústrias químicas. }\end{array}$}} \\
\hline$b$ & & & & \\
\hline C & & & & \\
\hline
\end{tabular}

Tabela (1) - Classe de agressividades ambiental, Fonte: NBR 6118:2014, p, 17 item 
Outra alteração importante foi a resistência mínima do concreto estrutural mínima 9 MPa passou a ser 20 MPa.

\title{
3.2- Esforços devido a carga de vento
}

Ação do vento era desprezada na maior parte dos edifícios, hoje na NBR 6123 é dada como obrigatória essa consideração.

\begin{abstract}
Será exigida a consideração da ação do vento nas estruturas em que esta ação possa produzir efeitos estáticos ou dinâmicos importantes e obrigatoriamente com estruturas com nós deslocáveis, nos quais a altura seja maior que 4 vezes a largura menor, ou em que em uma dada direção, o número de filas de pilares seja inferior a 4 . Deverá ser levado em conta a possível influência desfavoráveis em construções próximas as estruturas em exame, que por suas dimensões e forma possam tornar essa influência considerável.
\end{abstract}

(ASSOSSIAÇÃO BRASILEIRA DE NORMAS TÉCNICAS,1979, p.5)

Como cita a NBR 6118/03 (item 11.4.1.2), "Os esforços devidos à ação do ventodevem ser considerados e recomenda-se que sejam determinados de acordo com o prescritopela ABNT NBR 6123". Como antes na norma NBR-78 eram impostos coeficientes que permitiam desprezar a ação do vento na estrutura, o vento passou a ser um item obrigatório a ser analisado, não levando em consideração ao número de pavimentos, área construída e outros, o que implica em modificações cruciais na determinação dos esforços solicitantes nos elementos. O modelo básico de viga contínua, que simplesmente é apoiada nos pilares e analisadas separadamente dos outros elementos, não permite considerar de forma eficiente os esforços impostos pela carga de vento, deve-seser limitadas a projetos com baixa altura e poucos pavimentos. Em contrapartida, os programas que analisam as estruturas como um todo, analisando como pórtico espacialvem ganhando cada vez mais espaço no mercado Engenharia Civil, a forma ensinada de analise linear é ensinada e passada por grande parte das faculdades de engenharia, dimensionamento separadamente cada um dos item que compõe a estrutura. 
Na NBR 6118/1978 a análise era feita de modo distintas, tratando cada dimensionamento dos elementos estruturais separadamente, na norma mais atual a integração da estrutura passou a ter uma importância muito grande, pois dessa análise, espera-se resultados mais próximos da realidade.

Outras mudanças são em relação a cobrimento mínimo que passou de 1,5 da NBR $6118 / 2008$ para $2,5 \mathrm{~cm}$ e também a altura mínima de uma laje maciça que passa de 7 para $8 \mathrm{~cm}$. 


\section{4 - CONSIDERAÇÕES DECÁLCULO}

Este capítulo aborda alguns principais valores e conceitos de cálculo a serem considerado, juntamente com uma explicação de funcionamento do software EBERICK V9, os dois métodos usaram a mesma arquitetura para o projeto estrutural, classe de agressividade, alocação dos elementos estruturais, pé direito estrutural, cargas permanentes e acidentais.

\section{1 - Valores a serem considerados método manual de cálculo.}

O cálculo é estabelecido em função dos valores próprios e de coeficientes de segurança das resistências. Os coeficientes levam em conta sempre a variedade dos materiais envolvidos no projeto e também as dessemelhanças entre as solicitações últimas medidas em corpos de provas e no projeto estrutural, aproximações e desvios ocorridos no projeto, levando em consideração as resistências (ABNT, 2003).

Valores normalmente considerados para as resistências, fk, valores de um material tem uma certa chance de serem atingidos e ultrapassados, e colocando em risco a segurança. Existe também os dos valores médios das resistências, fm, existem os valores da resistência característica inferior, fk,inf, e superior,fk,sup.Normalmente é de interesse fk,inf, pois seu valor é menor que fm.

\subsection{1 - Estado Limites de Desempenho}

Estado limite ultimo (ELU), é ligado ao síncope, ou alguma ruína de estrutura que dar-se como encerrada o uso da estrutura.

Estado limite de serviço (ELS). São diretamente ligados a aparência , durabilidade, conforto em sua utilização pelos usuários ou equipamentos diversos. 
Estes estados Limites, são ligados diretamente ao bom dimensionamento e verificações.

Estado limite último "São aqueles relacionados ao colapso, ou a qualquer outra forma de ruína estrutural, que determine a paralisação do uso da estrutura" (CAMACHO,2005, p.8)

Estado limite de serviço são aqueles que correspondem à impossibilidade do uso normal da estrutura, estando relacionados à durabilidade das estruturas, aparência, conforto do usuário e a boa utilização funcional da mesma, seja em relação aos usuários, seja às máquinas e aos equipamentos utilizados (CAMACHO,2005, p.8)

\subsection{2 - Ações permanentes e variáveis.}

Ações permanentes são as que ocorrem com valores praticamente constantes durante toda a vida da construção, denominada carga permanente (CARVALHO FIGUEREDO, 2007)

Ações varáveis indiretas são constituídas por cargas acidentais previstas para uso da construção pela ação do vento e da chuva devendo-se respeitar as prescrições feitas por normas brasileiras especificas (CARVALHO FIGUEREDO,2007)

Carga permanente, segundo (ABNT1980) esta carga é formada pelo peso próprio da estrutura e também por todo o peso dos elementos construtivos fixos e instalações permanentes.

Carga acidental, segundo (NBR 6120,1980 ), é toda aquela que pode atuar sobre a estrutura de edificações em função do seu uso (pessoas, móveis, materiais diversos, veículos etc). 


\subsection{3 -Critérios de pré-dimensionamento de Lajes,Vigas e Pilares.}

No pré-dimensionamento depois de definida a planta arquitetônica do projeto, com a locação estratégicas dos pilares visando melhor ajudar na arquitetura e acabamentos como também facilitar os cálculos necessários para com o projeto, para os pilares suas dimensões adotadas serão de $15 \times 45$ para o pré dimensionamento.

As vigas, será altura da seção das vigas é de 1/10 do vão, única condição estipulada para pré-dimensionamento das vigas.

Para o pré-dimensionamento das lajes, deverá ser efetuado alguns cálculos simples para definição de sua altura e direções de armaduras.Para obtenção desse valor, adotaremos a seguinte fórmula:

$$
\varepsilon=\mathrm{ly} / \mathrm{lx}
$$

Uma classificação muito importante das lajes maciças é aquela referente à direção ou direções da armadura principal. Existem dois casos: laje armada em uma direção ou laje armada em duas direções.

Se o resultado encontrado estiver entre $0,5<\varepsilon<2$ a laje será armada em duas direções se não, será armada em uma direção.

O modelo estático é definido quando a laje se engasta ou simplesmente apoia em outra laje para que seja engastada é necessário que as duas lajes que se encontram não possuam desnível entre elas superior a $10 \mathrm{~cm}$, e livre é quando a laje encontra-se em balanço.

O resultado deste cálculo é a altura de pré-dimensionamento que adotaremos, caso a altura encontrada seja menor que $10 \mathrm{~cm}$ que é a altura mínima permitida pela norma NBR 6118:2014, seguiremos a norma e adotaremos $10 \mathrm{~cm}$.

Para automatização de tais procedimentos de cálculo, foi desenvolvido uma ferramenta baseada na plataforma Microsoft Office Excel 2013, otimizando assim as rotinas de cálculo conforme exemplo da figura (8) referente a laje 19 do projeto. 


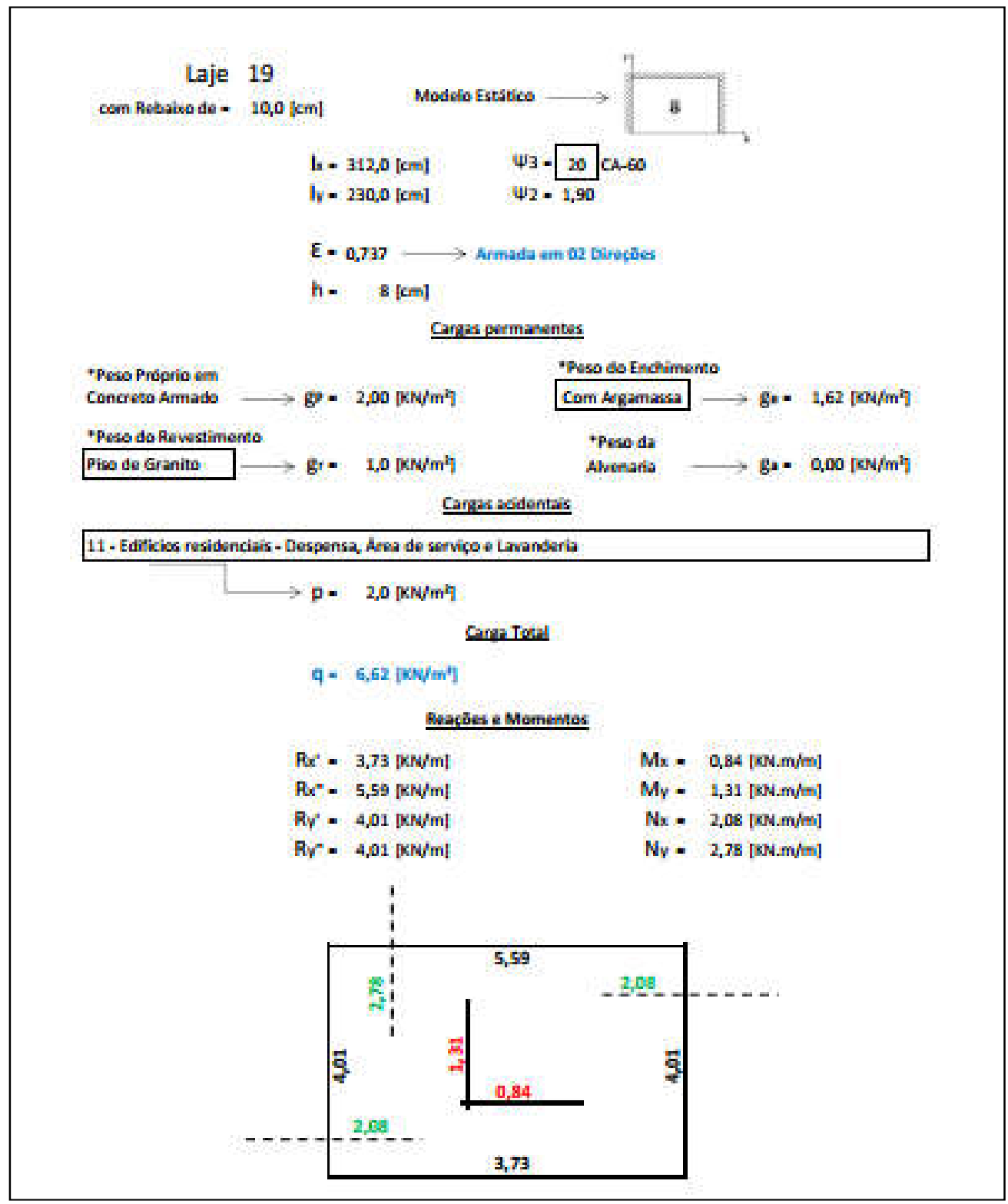

Figura (8) - Ferramenta de pré-dimensionamento Fonte: Autores ( 2016 )

\subsection{4 - Dimensionamento da amadura das Lajes}

Para o dimensionamento da armadura da laje é necessário que esteja definido as cargas atuantes e os momentos fletores nas respectivas lajes. Seguindo a linha de cálculo a seguir: 
'Kd' para que se tenha um elemento dútil verifica-se a parcela referente a altura útil.

$$
\mathrm{kd}=\frac{\mathrm{d}}{\sqrt{\frac{\mathrm{Md}}{\mathrm{fck} \cdot 1,0}}}
$$

Para Kz vide tabela (2) em função de Kd .

\begin{tabular}{|c|c|c|c|c|c|c|c|c|c|c|c|c|}
\hline \multirow{2}{*}{ Ky } & \multirow[b]{2}{*}{$\mathcal{E}_{8 \%}$} & \multirow{2}{*}{$\mathrm{Kz}$} & \multirow{2}{*}{$\mathrm{Kd}$} & \multirow{2}{*}{$\mathrm{Km}$} & \multicolumn{8}{|c|}{ fsd (MPa) } \\
\hline & & & & & $\overline{C A 25}$ & CA 32 & CA 40A & CA 408 & CA 50A & CA 508 & CA $60 A$ & CA 608 \\
\hline 0,020 & & & 9.120 & & & & & & & & & \\
\hline 0,040 & & & 6,480 & & & & & & & & & \\
\hline 0,060 & & & 5,320 & & & & & & & & & \\
\hline 0,080 & & & 4,630 & & & & & & & & & \\
\hline 0,100 & & & 4,160 & & & & & & & & & \\
\hline 0,120 & & & 3,820 & & & & & & & & & \\
\hline 0,140 & & & 3,560 & & & & & & & & & \\
\hline 0,160 & & & 3,350 & & & & & & & & & \\
\hline 0,180 & & & 3,170 & & & & & & & & & \\
\hline 0,200 & & & 3,030 & & & & & & & & & \\
\hline 0,207 & 1,000 & 0.897 & 2,980 & 0,113 & & & & & & & & \\
\hline 0,210 & 0,923 & 0,895 & 2,960 & 0,114 & & & & & & & & \\
\hline 0,220 & 0,922 & 0.890 & 2,900 & 0,118 & & & & & & & & \\
\hline 0,230 & 0,867 & 0,885 & 2,840 & 0,123 & & & & & & & & \\
\hline 0,240 & 0,817 & 0,880 & 2,790 & 0,128 & & & & & & & & 522 \\
\hline 0,250 & 0,770 & 0.875 & 2,750 & 0,132 & & & & & & & & \\
\hline 0,260 & 0,726 & 0,870 & 2,700 & 0,137 & & & & & & 435 & & \\
\hline 0,270 & 0,697 & 0,865 & 2,660 & 0,141 & & & & & & & & \\
\hline 0.280 & 0,650 & 0,860 & 2,620 & 0,146 & & & & 348 & & & & \\
\hline 0,290 & 0,616 & 0,855 & 2,580 & 0,150 & & & & & & & & \\
\hline 0,300 & 0,583 & 0.850 & 2,540 & 0,154 & & & & & & & & \\
\hline 0,310 & 0,553 & 0,845 & 2,500 & 0.159 & & & & & & & 522 & \\
\hline 0,320 & 0,525 & 0,940 & 2,470 & 0,163 & & & & & & & & \\
\hline 0,330 & 0,498 & 0.835 & 2,440 & 0,167 & & & & & & & & \\
\hline 0,340 & 0,474 & 0,830 & 2,420 & 0,171 & & & & & 435 & & & \\
\hline 0,350 & 0,450 & 0,825 & 2,390 & 0,175 & & & & & & & & 522. \\
\hline 0,360 & 0,428 & 0,820 & 2,360 & 0,180 & & & 348 & & & & & 515 \\
\hline 0,369 & 0.407 & 0,816 & 2,340 & 0,183 & & & & & & 435 & & 509 \\
\hline 0,370 & 0,406 & 0.815 & 2.340 & 0,183 & & & & & & 434 & & 507 \\
\hline 0,380 & 0,387 & 0,810 & 2,310 & 0,187 & & 278 & & & & 429 & & 500 \\
\hline 0,390 & 0,370 & 0,805 & 2,290 & 0,190 & & & & & & 424 & & 494 \\
\hline 0.400 & 0,350 & 0,800 & 2,270 & 0,194 & 217 & & & 348 & & 418 & & 486 \\
\hline 0,410 & 0,333 & 0,795 & 2,250 & 0,198 & & & & 340 & & 412 & & 478 \\
\hline 0,420 & 0,317 & 0,790 & 2,220 & 0.202 & & & & 336 & & 407 & & 472 \\
\hline 0,430 & 0,301 & 0,785 & 2,210 & 0,205 & & & & 331 & & 401 & & 464 \\
\hline 0.440 & 0,286 & 0,780 & 2,190 & 0,207 & & & & 327 & & 395 & & 457 \\
\hline 0,450 & 0,272 & 0,775 & 2,170 & 0,211 & & & & 324 & & 390 & & 449 \\
\hline 0,460 & 0,259 & 0.770 & 2,150 & 0,215 & & & & 320 & & 385 & 5.22 & 442 \\
\hline 0,470 & 0,246 & 0,765 & 2,140 & 0.218 & & & & 315 & & 379 & 517 & 434 \\
\hline 0,480 & 0,233 & 0,760 & 2,120 & 0,221 & & & & 311 & & 373 & 490 & 426 \\
\hline 0.490 & 0,221 & 0.755 & 2,100 & 0,224 & & & & 307 & & 367 & 464 & 417 \\
\hline 0,500 & 0,210 & 0,750 & 2,090 & 0,227 & 217 & 278 & 348 & 303 & 435 & 361 & 441 & 409 \\
\hline \multicolumn{13}{|l|}{ Legenda: } \\
\hline \multicolumn{3}{|l|}{ DỨTL } & & & & & & & & & & \\
\hline \multirow{2}{*}{\multicolumn{3}{|c|}{ SUBAREMADA }} & & & & & & & & & & \\
\hline SUPERA & & & & & & & & & & & & \\
\hline
\end{tabular}

Tabela (2) - Coeficientes Kd e Kz. 
Deste modo pode-se determinar a área de aço As por metro;

$$
\text { As }=\frac{\text { Md }}{\text { Fsd. Kz.d }}
$$

Como a área de aço é definida por metro, adota-se um diâmetro de ferro e estuda-se essa bitola escolhida.

$$
N=\frac{A s}{A s \emptyset}
$$

Sendo; $\mathrm{N}$ = número de ferros necessários por metro

As $\varnothing=$ Área de aço por ferro adotado

O espaçamento [S] da armadura é determinada pela seguinte expressão:

$$
S=\frac{100}{N}
$$

Logo, para simplificação da mão de obra e para este trabalho, o espaçamento será adotado com uma variação de $2,5 \mathrm{~cm}$, ou seja, $1 \varnothing \mathrm{c} / 5 \mathrm{~cm}, 1 \varnothing \mathrm{c} / 7,5 \mathrm{~cm}, 1 \varnothing \mathrm{c} / 10 \mathrm{~cm}$.

Para a definição do comprimento da armadura, neste trabalho foi considerado o conceito de economia de ponta que tem como característica o posicionamento dos ferros de modo alternados visando diminuir o comprimento efetivo de tal que vença todo o diagrama de momento fletor. Obtendo assim um dimensionamento preciso e econômico.

Para automatização dos procedimentos de cálculo das armaduras positivas e negativas, foi desenvolvida a seguinte ferramenta, como mostra a figura (9) e a figura (10) referente a laje 19 do projeto. 


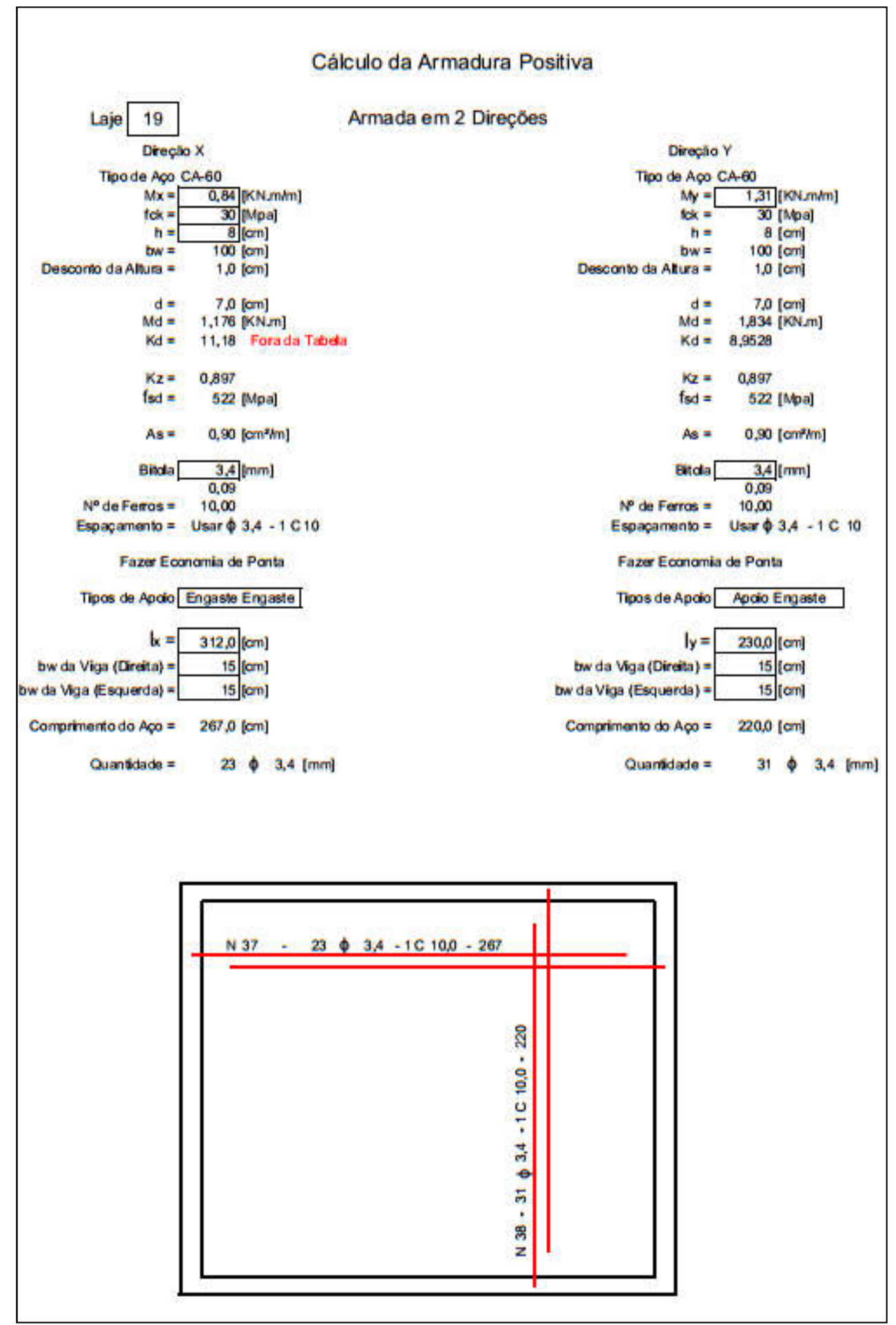

Figura (9) - Ferramenta de dimensionamento da armadura positiva. Fonte: Autores ( 2016 ) 


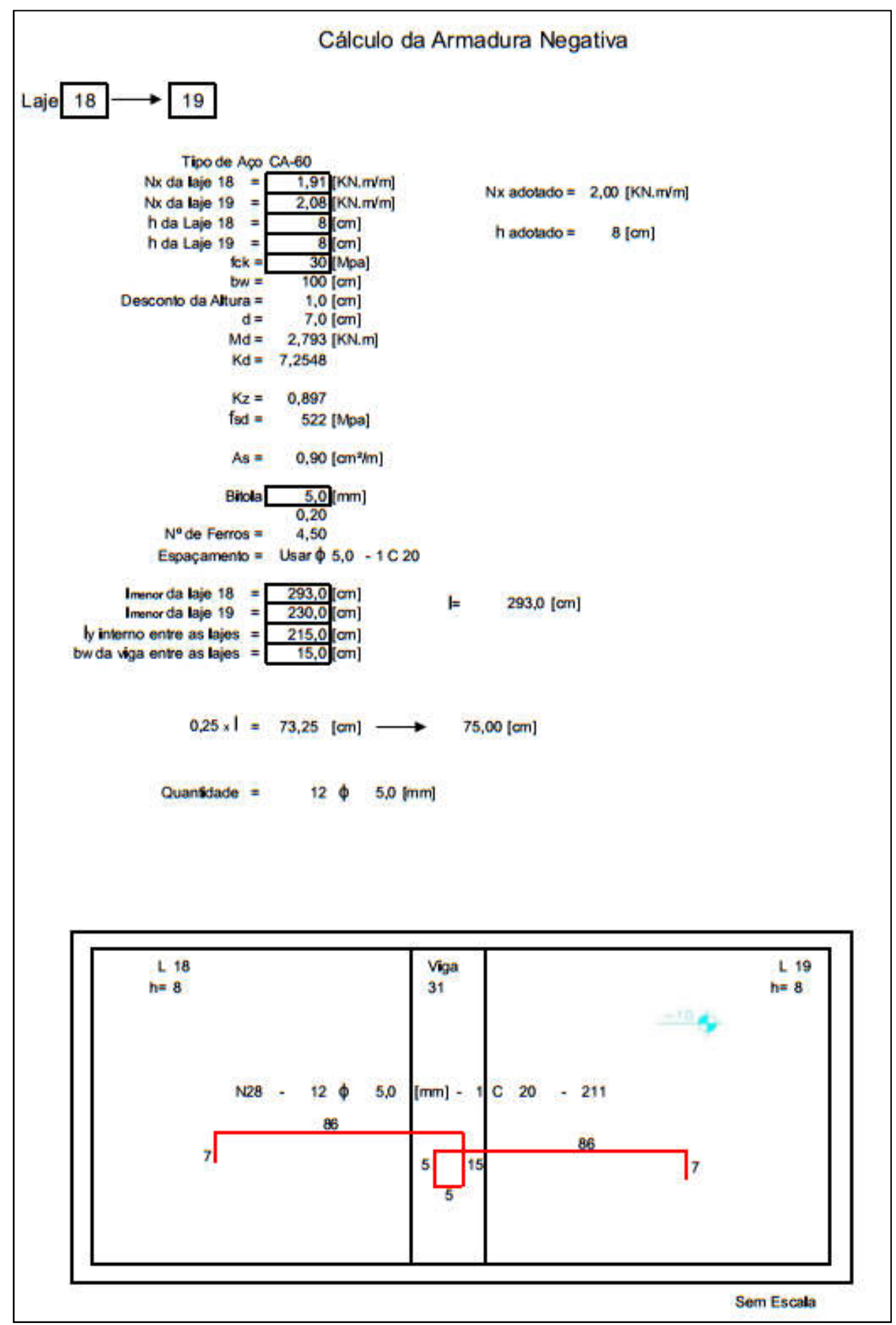

Figura (10) - Ferramenta de dimensionamento da armadura negativa,Fonte: Autores ( 2016 ) 


\subsection{5 - Dimensionamento da amadura das vigas de flexão simples}

A flexão normal simples é aquela em que além do plano de flexão conter um dos eixos principais de inércia, não há presença de força normal. Na flexão normal simples a linha neutra situa-se entre a borda comprida da seção e a armadura tracionada e ocorrem nos domínios 2,3 e 4 de deformação, o dimensionamento do concreto armado na flexão simples, no estado de ruptura ( Estado de Limite último ) E.L.U, faz-se com os seguintes hipóteses ( ABNT, 2003 ):

- As seções se mantém plana após a deformação ( hipótese de Berdoulli );

- A deformação das barras da armadura passiva, em tração ou compressão, é a mesma do concreto em sua volta;

- O encurtamento máximo do concreto, isto é, da fibra mais afastada da linha neutra, é de 3,5\%;

- A tensão máxima de compressão do concreto é de 0,85 do valor da resistência 0,85 do valor da resistência característica a compressãofck;

- As tensões de tração no concreto, normais a seção transversalsão desprezadas, obrigatoriamente, no E.L.U;

- A distribuição de tensões no concreto se faz de acordo com o diagrama parábola-retângula. Esse diagrama pode ser substituído pelo retângulo de altura $0,8 x$, onde $x$ é a profundidade da linha neutra;

- A tensão nas armaduras de aço deve ser obtidas a parte dos diagramas de cálculo $\sigma-\varepsilon$;

- O alongamento máximo do aço da armadura de tração e de 1,0\%, para evitar deformação plásticas excessivas no E.L.U;

- O encurtamento de ruptura do concreto é de $0,2 \%$, na compressão simples,e de $0,35 \%$, na flexão simples.

- No dimensionamento de vigas e lajes a flexão normal simples pode-se observar três casos ( NBR- 6110, 2003 );

- Domínio 2 - sem ruptura a compressão do concreto ( $\varepsilon s<3,5 \%$ e com o máximo alongamento permitido );

- Domínio 3 - escoamento do aço com ruptura compressão do concreto ( $\mathcal{E} \mathbf{s} \geq$ Esyd) - seção subarmada; 
- Domínio 4 - o aço tracionado abaixo do limite de escoamento e o concreto com a ruptura a compressão ( $\mathcal{E} \mathbf{s}<\boldsymbol{\varepsilon}$ syd) - seção supearmada.

Na figura (11) é mostrado o estado - limite último de uma seção transversal.

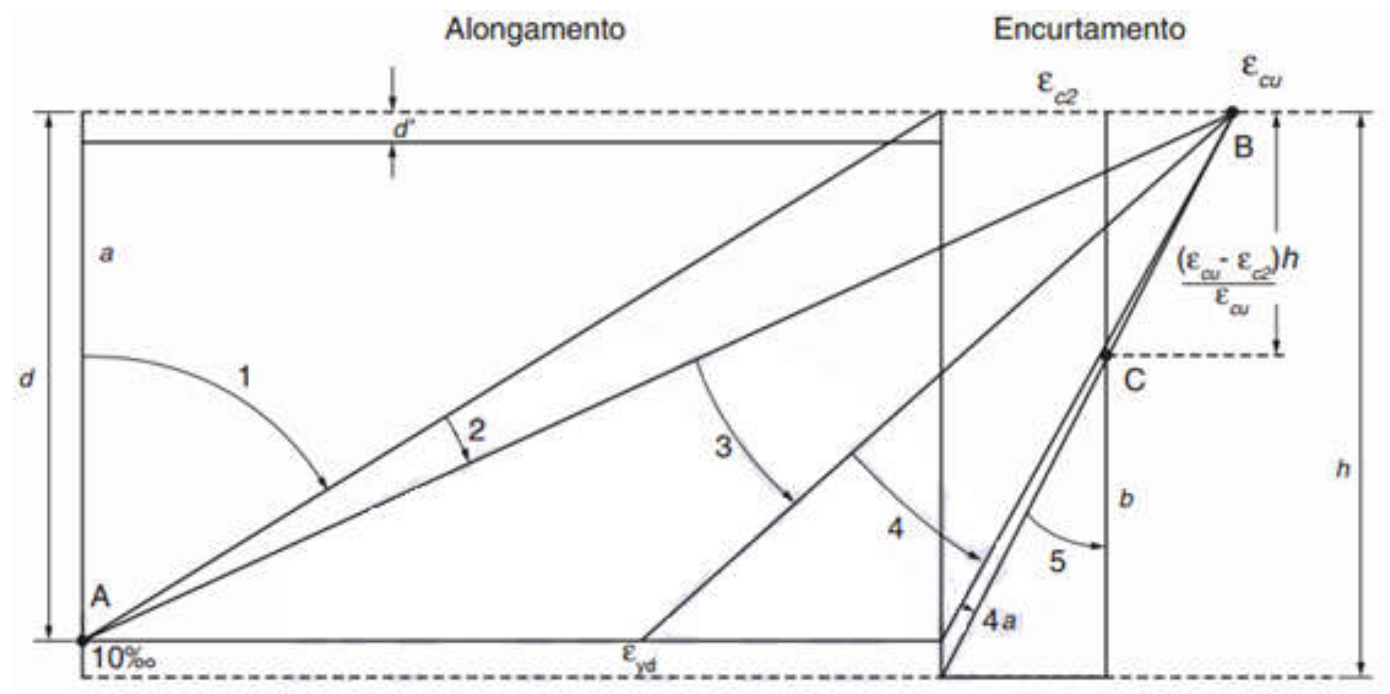

Figura (11) .Domínio de estado limite último de uma seção transversal ( NBR 6118 / 2014 )

As principais formulas e suas devidas utilidades são:

'Kd' para que se tenha um elemento dútil.

$$
\mathrm{kd}=\frac{\mathrm{d}}{\sqrt{\frac{\mathrm{Md}}{\mathrm{fck.bw}}}}
$$

Deste modo pode-se determinar a área de aço As;

$$
\text { As }=\frac{\text { Md }}{\text { Fsd. Kz.d }}
$$

$\mathrm{Kz}=$ Parcela referente ao braço de alavanca.

Da lei de Hooke, pode-se determinar a deformação do aço

$$
\varepsilon S=\frac{\text { fsd }}{\text { Es }}
$$




\subsection{6 - Método de Dimensionamento das Vigas ao Cisalhamento}

A resistência da peça é assegurada pela verificação da compressão diagonal do concreto seguindo a norma ( NBR 6118,2003 ):

$\operatorname{Vrd} 2=0,27 . \alpha v$. fcd. bw. $d>$ Vsdonde:

Vsd $=(1,4 . \mathrm{V})$; cortante de cálculo;

Parcela de cortante absorvida pelo concreto;

$$
\mathrm{Vc}=(0,6 . \text { fctdinf. bw. } \mathrm{d})
$$

Assim,Vrd2 > Vsd, ok , seção compatível, podemos calcular a armadura transversal ' Vsw':

$$
\mathrm{Vsw}=\mathrm{Vsd}-\mathrm{Vc}
$$

Depois cálculo do espaçamento entre estribos :

$$
\mathrm{s}=\frac{\text { p. ase. } 0,9 \cdot \mathrm{d} \cdot \mathrm{fyd}}{\text { Vsw }}
$$

onde:

$(P)$ número de pernas do estribo;

(ase) área do estribo;

Armadura mínima:

$$
\operatorname{smax}=\frac{P \cdot \text { ase } \cdot \text { fyk }}{0,2 \cdot \text { bw. fctm }}
$$

Prescrições da ( NBR - 6118,2003 )

$$
\mathrm{s}<\text { smax; }
$$

Diâmetro do estribo $\leq \frac{\mathrm{bw}}{10}$

Espaçamento longitudinal, Vsd $=0,67$. VRd2, então $\operatorname{smax} \leq 30 \mathrm{~cm}$ 


\subsection{7 - Método para Ancoragem das Armaduras}

Para que haja solidariedade entre aço e concreto é necessário que exista entre ambos aderência que impeça o escorregamento de um em relação ao outro ( JOST, 1970 ).

A resistência de aderência dar-se, fbd $=\eta 1 . \eta 2 . \eta 3$. fctd,inf, sendo ( NBR 6118, 2003):

$\eta=$ coeficiente de aderência, entre aço e concreto;

१1 = para aço liso, entalhado ou nervurado;

ฤ2 = em situações de boa ou má aderência;

$\eta 3$ = relacionado com diâmetro da barra .

Tensões admissíveis do concreto ( NBR 6118, 2003 ):

$f c t m=0,3(f c k)^{\frac{2}{3}}$, Resistência média a tração do concreto;

fctk, inf $=0,7 . f c t m$, Resistência característica a tração inferior;

$f c t d$, inf $=\frac{f c t k, \text { inf }}{1,4}$, Resistência característica a tração inferior de cálculo;

$f c d=\frac{f c k}{1,4}$, Tensão de compressão de cálculo do concreto.

Ancoragem das armaduras é o comprimento mínimo de uma barra necessário para transferir sua força ao concreto e as barras devem-se ser ancoradas para que os esforços sejam transmitidos ao concreto(NBR 6118/2003 ).

$$
\ell \mathrm{b}=\left(\frac{\Phi}{4}\right) \cdot\left(\frac{\mathrm{fyd}}{\mathrm{fbd}}\right)
$$

Onde:

$\Phi=$ diâmetro do aço; 


$$
\text { fyd }=\frac{\text { fyk }}{1,4}
$$

Comprimento de ancoragem necessário:

$$
\ell b n e c=\ell b .\left(\frac{\text { As calculado }}{\text { As efetivo }}\right),
$$

onde:

As calculado = área de seção calculado;

As efetivo =área efetiva (adotada).

Comprimento de ancoragem mínimo, segundo ( NBR 6118, 2003 ):

$\ell$ bmin $\geq 0,3 \mathrm{lb}, 10 \Phi$ ou $10 \mathrm{~cm}$.

Para automatização dos procedimentos de cálculo de dimensionamento das vigas, foi desenvolvida a seguinte ferramenta, como mostra a figura (12) . 


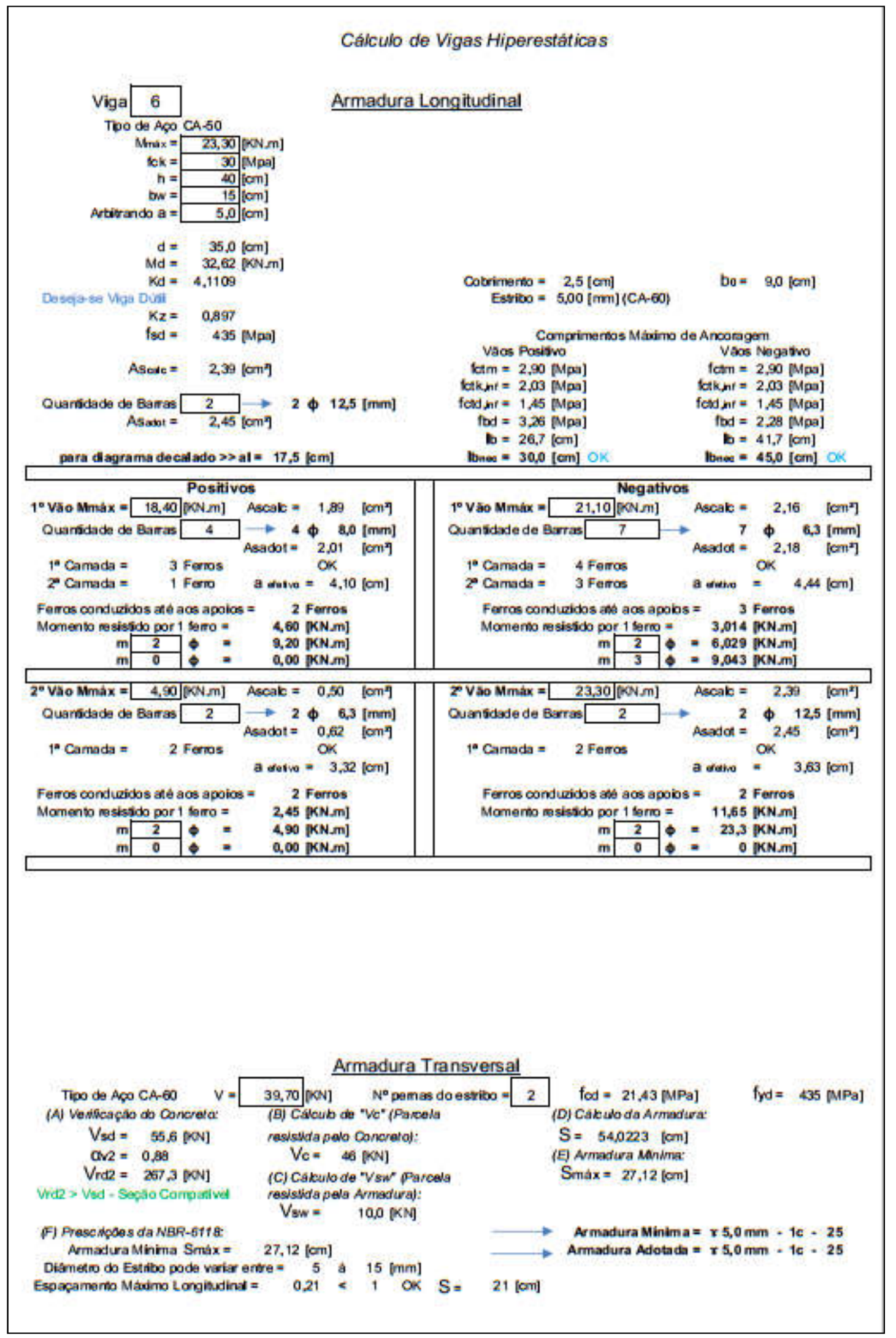

Figura (12) - Ferramenta de dimensionamento das vigas,Fonte: Autores (2016) 


\subsubsection{Dimensionamento de pilares}

Esforços normal de cálculo:

- Coeficientes de majoração com b $\geq 20 \mathrm{~cm}$, então $\gamma f=1,40$

- Coeficiente de majoração $b \leq 20 \mathrm{~cm}, \mathrm{\gamma} f=1,40$

- Condição de estabilidade $\mathrm{N} \geq \mathrm{d}$

Diâmetro mínimo das barras longitudinais não deverá der menor que $10 \mathrm{~mm}$ nem superior $1 / 8$ da menor dimensão transversal (b);

Armadura longitudinal mínima ;

$$
\text { Asmin }=0.15 \times\left(\frac{N d}{f y^{\prime} d}\right) \geq 0,004 \times A c
$$

Onde;

Ac $=$ área da seção do concreto

Armadura longitudinal máxima ;

$$
A s_{\text {máx }}=0,08 \cdot A c
$$

Armaduras transversais.

A função principal dos estribos e grampos é de conter a flambagem local e devem ser considerados em toda a extensão do pilar.

Para automatização dos procedimentos de cálculo de dimensionamento dos pilares, foi desenvolvida a seguinte ferramenta, como mostra a figura (13) . 


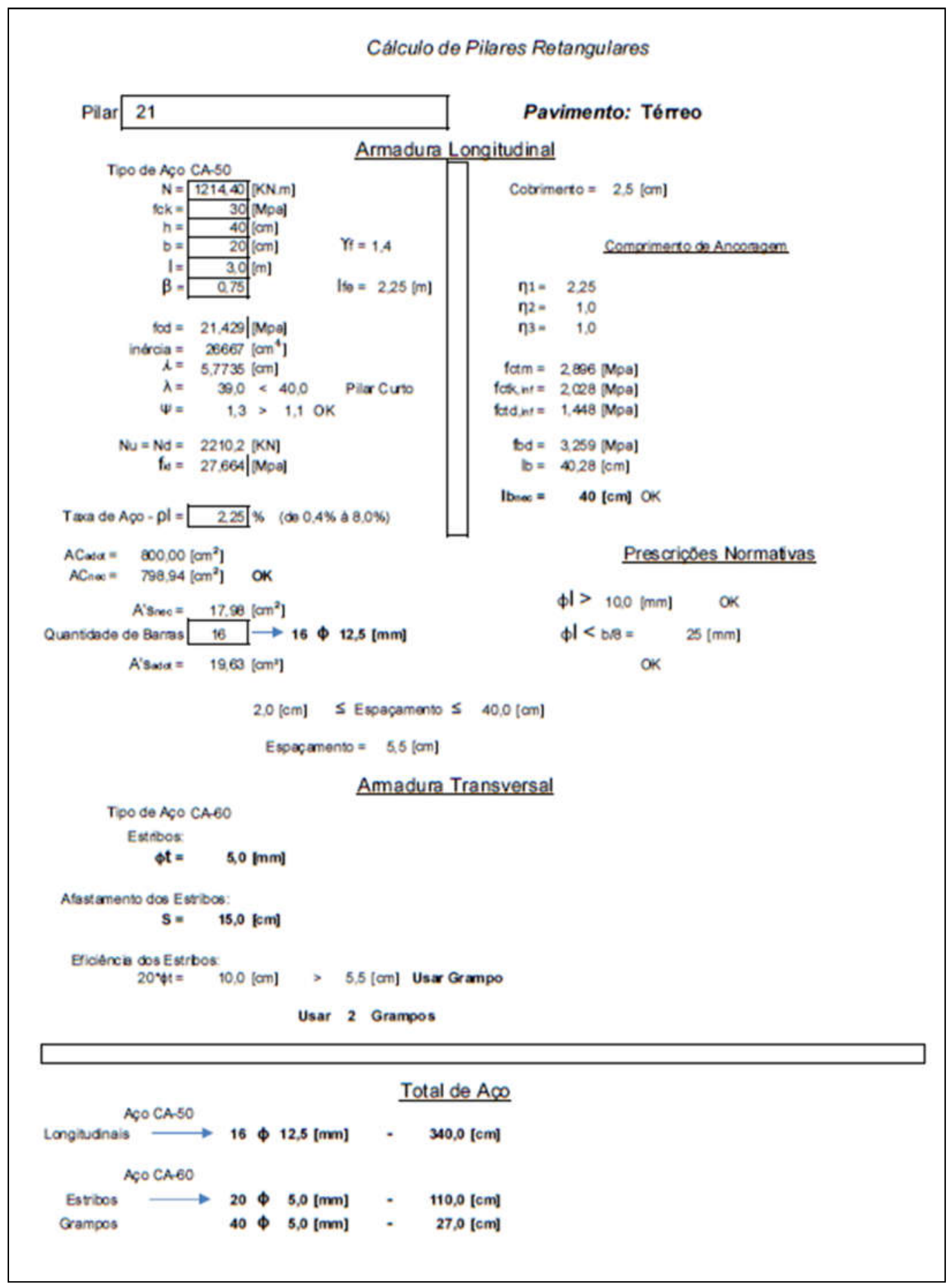

Figura (13) - Ferramenta de dimensionamento dos pilares,Fonte: Autores (2016) 


\subsection{Considerações e critérios adotados no dimensionamento de Lajes feitas pelo Software EBERICK V9.}

Para início do projeto no software é necessário que se importe a arquitetura já definida em um ambiente CAD, a partir daí o software faz a conversão para a escala mais adequada. Com isso lança-se os primeiros elementos do projeto que são os pilares,faz-se necessário que o operador do software informe alguns dados como as dimensões dos pilares e seus vínculos, feito isso basta apenas locar os pilares em seus respectivos lugares com base na planta de arquitetura. É válido lembrar que todas as funções do software são de acordo com a NBR 6118:2014 de modo que, caso haja alguma inconsistência ou algo que não atenda às necessidades da norma, automaticamente o Eberick emite um aviso não deixando assim processar a estrutura. Já locado os pilares conforme as especificações do profissional calculista é hora de criar as vigas do projeto, da mesma forma que foi lançado os pilares é necessário novamente informar as dimensões das vigas, assim como cobrimento e vínculos. Tanto no caso das vigas como nos pilares, o Eberick V9 oferece diversos tipos de seções sendo alguma delas no caso de vigas, vigas em T, vigas chatas ou vigas "faixas" e até mesmo vigas com seções compostas. Já locados os pilares e as vigas é hora de fazer o lançamento das lajes, sendo assim podendo adotar lajes maciças, lajes nervuradas ou lajes pré fabricadas. Para o projeto adotado irá ser utilizado lajes maciças que para ser introduzida no software basta limitar as áreas de concordância das vigas, formando assim uma área fechada para a laje.

Com todos os elementos estruturais lançados é preciso fazer um estudo de carga para informar ao software quais cargas Acidentais irão atuar no projeto de acordo com a NBR 6120. As cargas causadas pelo peso próprio da estrutura são calculadas automaticamente pelo software levando em consideração a geometria dos elementos sendo desnecessário o lançamento da mesma. Após todos os elementos lançados e cargas devidamente adotadas cria-se um modelo 3D da estrutura chamada Pórtico 3D, sendo que é pela análise em pórtico espacial que o Eberick determina todas as reações. Nessa análise é levado em consideração a estrutura como um modelo homogêneo com uma interação de todos os elementos estruturais. Ao processar a estrutura calcula-se os esforços e dimensiona-se os 
elementos de acordo com todas as informações inseridas no Eberick, sendo algumas delas o Fck (Resistência característica à compressão do concreto), classe de agressividade, bitolas de aço adotado ou até as características mecânicas do solo para o dimensionamento das fundações. Ao analisar cada elemento, o software nos mostra quais dos elementos não atenderam as necessidades do projeto de modo a solicitar que mude a seção do elemento ou que se tome alguma medida para fazer uma nova análise até que todos os elementos estruturais possam suprir as solicitações existentes. Há a possibilidade de analisar também separadamente todos os diagramas sejam eles de momentos fletores, cisalhamentos, carregamentos ou momentos torçores de modo a encontrar alguma inconsistência ou realizar uma análise mais apurada para um melhor entendimento da estrutura.

Com todos os elementos devidamente dimensionados é possível gerar relatórios sendo alguns deles: Relatório de cargas, que mostra as cargas nas fundações; relatórios de elementos, que fornece as dimensões de todos os elementos estruturais do projeto e também um completo relatório de materiais utilizadosque monta um quantitativo muito preciso de todos os materiais que irá ser utilizado no projeto como; quantidade de concreto em [ $\left.\mathrm{m}^{3}\right]$, peso total de aço em [Kg] e fôrmas em $\left[\mathrm{m}^{2}\right]$. Por fim, após tudo corretamente analisado, dimensionado e verificado geram-se as pranchas do projeto completo constando os detalhamentos dos elementos, as locações das fundações, plantas de fôrma e as tabelas de aço para a compra. 


\section{5- ANÁLISE DE RESULTADOS}

\section{1 - Comparativo das Lajes}

Com base no dimensionamento produzido em ambos os métodos, foi obtido os seguintes resultados a fim de comparação.

Para análise comparativa referente ao peso de aço e volume de concreto de toda a estrutura como demonstra o gráfico (1) e (2).

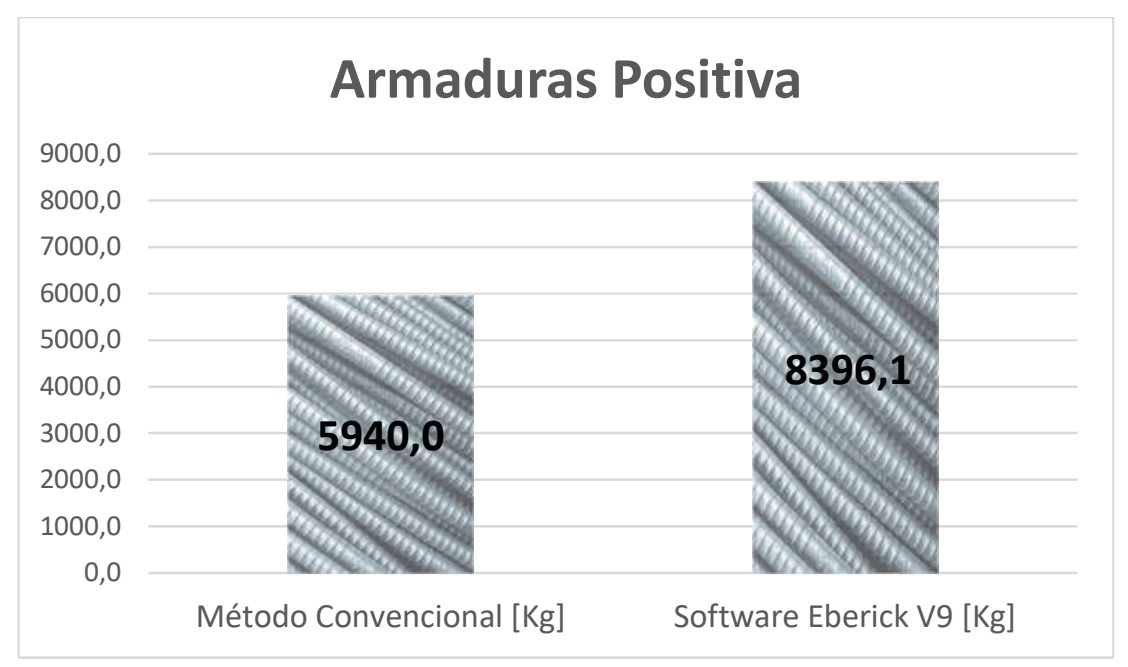

Gráfico (1) - Peso de Aço Armaduras Positiva da Laje, Fonte: Autores (2016)

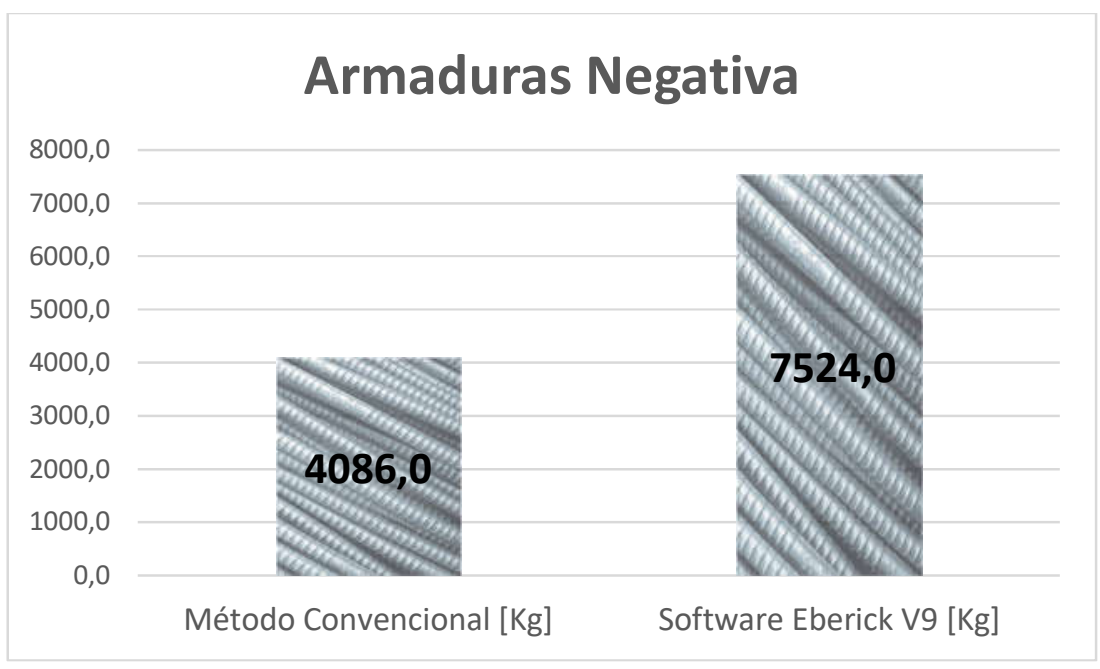

Gráfico (2) - Peso de Aço Armaduras Negativa da Laje, Fonte: Autores ( 2016 ) 
Com base nos dados obtidos o método de dimensionamento convencional apresentou uma economia de aproximadamente $60,0 \%$ das armaduras positivas e negativas das lajes de todo o projeto, em comparação ao desenvolvido via Software Eberick V9 conforme gráfico (3)

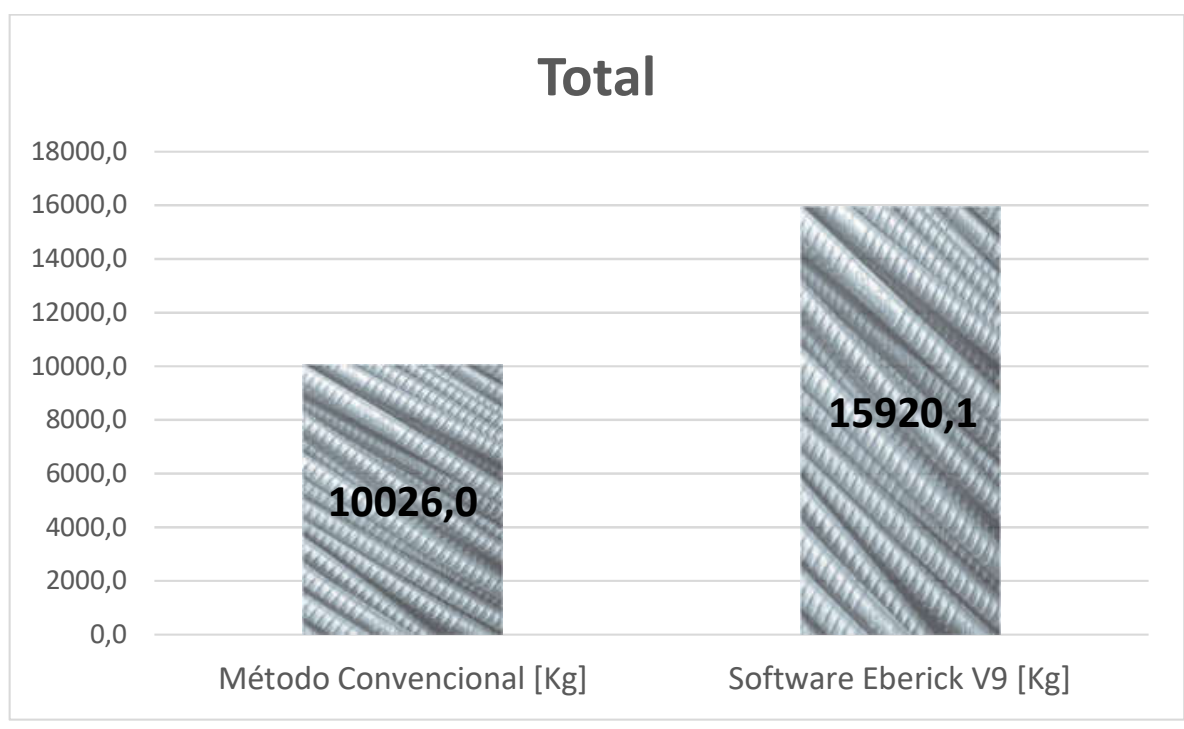

Gráfico (3) - Comparação Total das Armaduras de Laje, Fonte: Autores ( 2016 )

A análise comparativa referente ao volume de concreto de toda a estrutura apresenta uma economia de aproximadamente $16 \%$ no volume de concreto utilizado quando é dimensionado pelo método convencional de cálculo como segue demonstrado pelo gráfico (4).

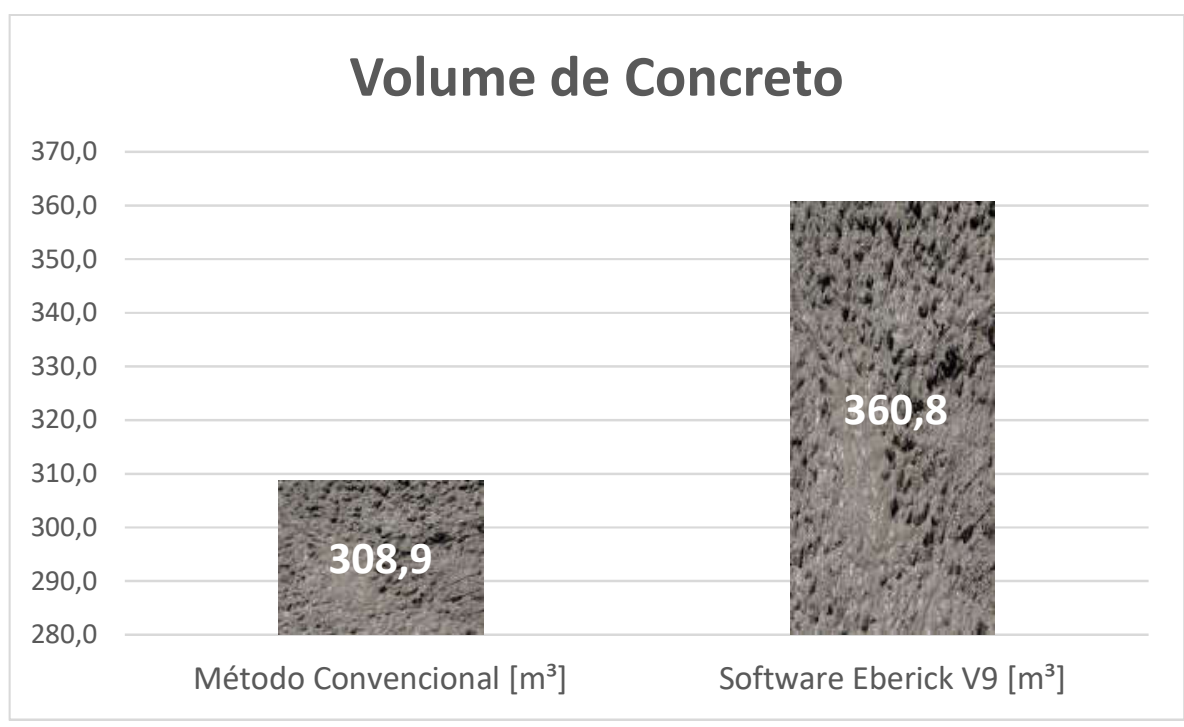

Gráfico (4) - Comparação Total de Concreto das Lajes,Fonte: Autores (2016). 


\section{2 - Comparativo das Vigas}

Com base no dimensionamento produzido em ambos os métodos, foi obtido os seguintes resultados a fim de comparação.

Para análise comparativa referente ao peso de aço e volume de concreto de toda a estrutura como demonstra o gráfico (5) e (6).

Com base nos dados obtidos o método de dimensionamento convencional apresentou uma economia de aproximadamente $21,0 \%$ das armaduras das vigas de todo o projeto, em comparação ao desenvolvido via Software Eberick V9 conforme gráfico (5)

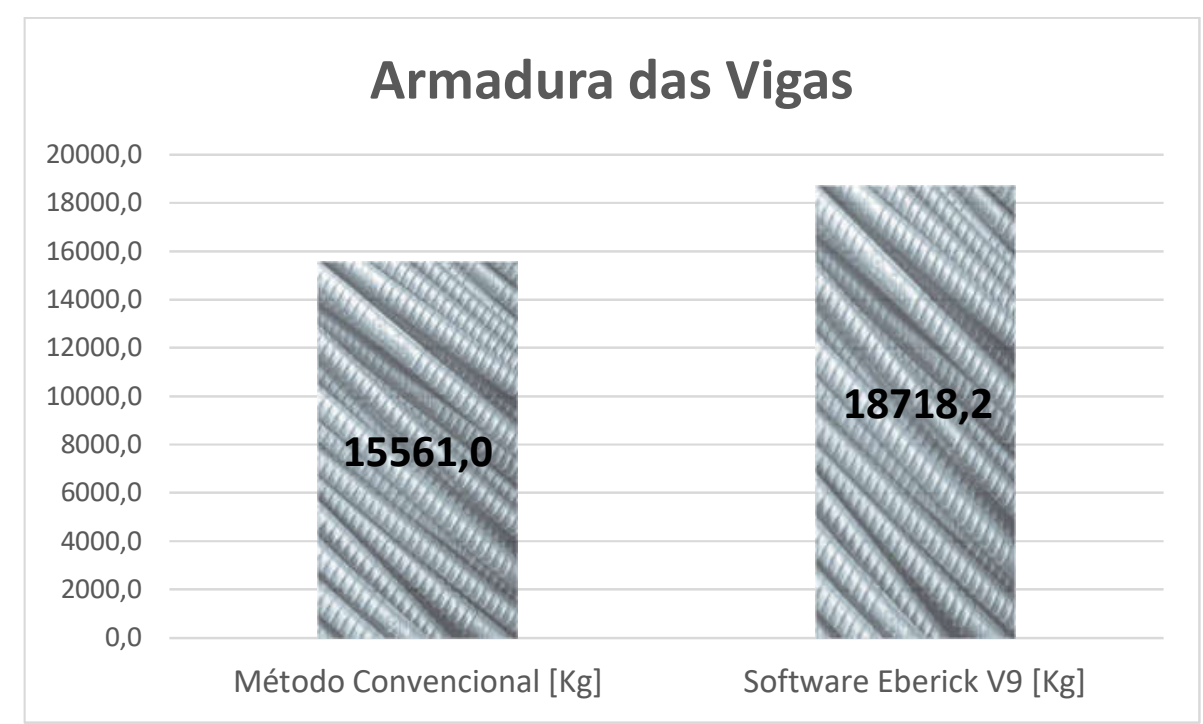

Gráfico (5) - Comparação Total das Armaduras de Vigas, Fonte: Autores(2016).

A análise comparativa referente ao volume de concreto das Vigas de toda a estrutura apresenta uma economia de aproximadamente $2 \%$ no volume de concreto utilizado quando é dimensionado pelo Eberick V9 de cálculo como segue demonstrado pelo gráfico (6) 


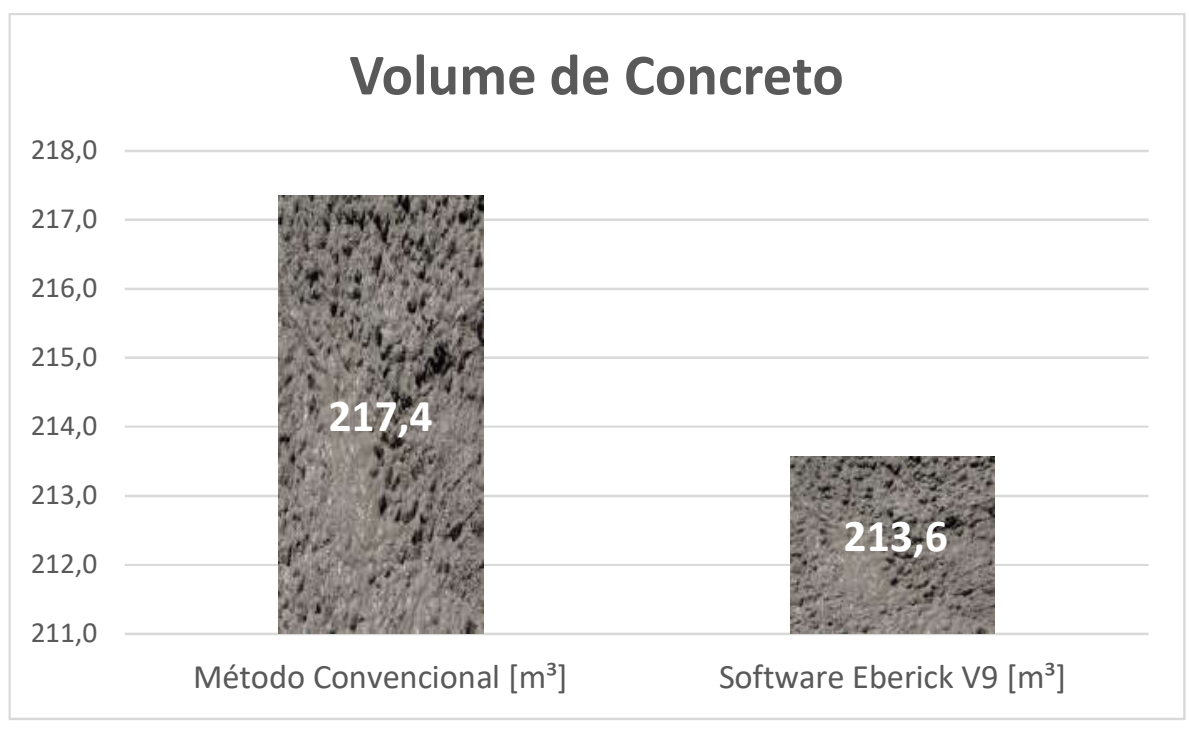

Gráfico (6) - Comparação Total de Concreto das Vigas, Fonte: Autores (2016).

\section{3 - Comparativo dos Pilares}

Com base no dimensionamento produzido em ambos os métodos, foi obtido os seguintes resultados a fim de comparação.

Para análise comparativa referente ao peso de aço e volume de concreto de toda a estrutura como demonstra o gráfico (7) e (8).

Com base nos dados obtidos o método de dimensionamento convencional apresentou uma economia de aproximadamente $65,0 \%$ das armaduras dos pilares de todo o projeto, em comparação ao desenvolvido via Software Eberick V9 conforme gráfico (7). 


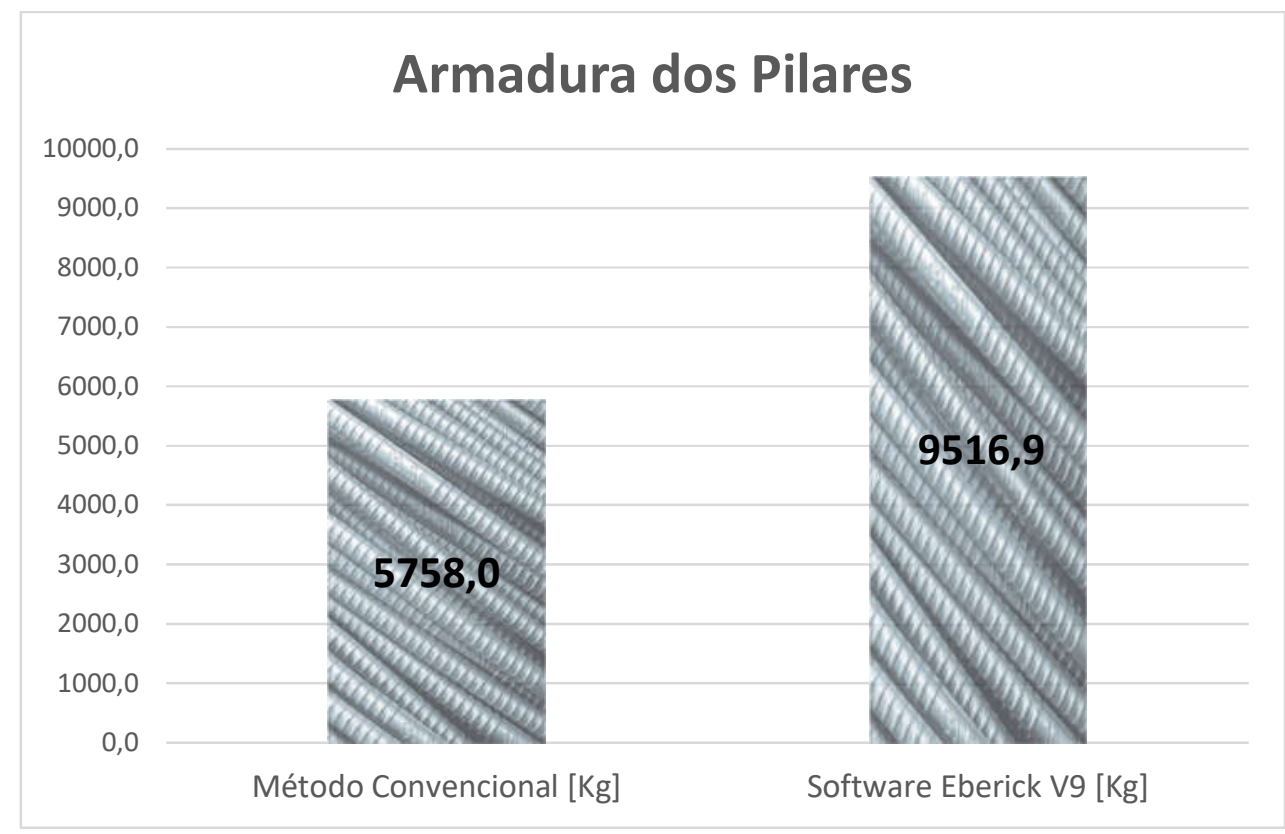

Gráfico (7) - Comparação Total das Armaduras dos Pilares, Fonte: Autores(2016).

A análise comparativa referente ao volume de concreto dos pilares de toda a estrutura apresenta uma economia de aproximadamente $26,1 \%$ no volume de concreto utilizado quando é dimensionado pelo Eberick V9 de cálculo como segue demonstrado pelo gráfico (8).

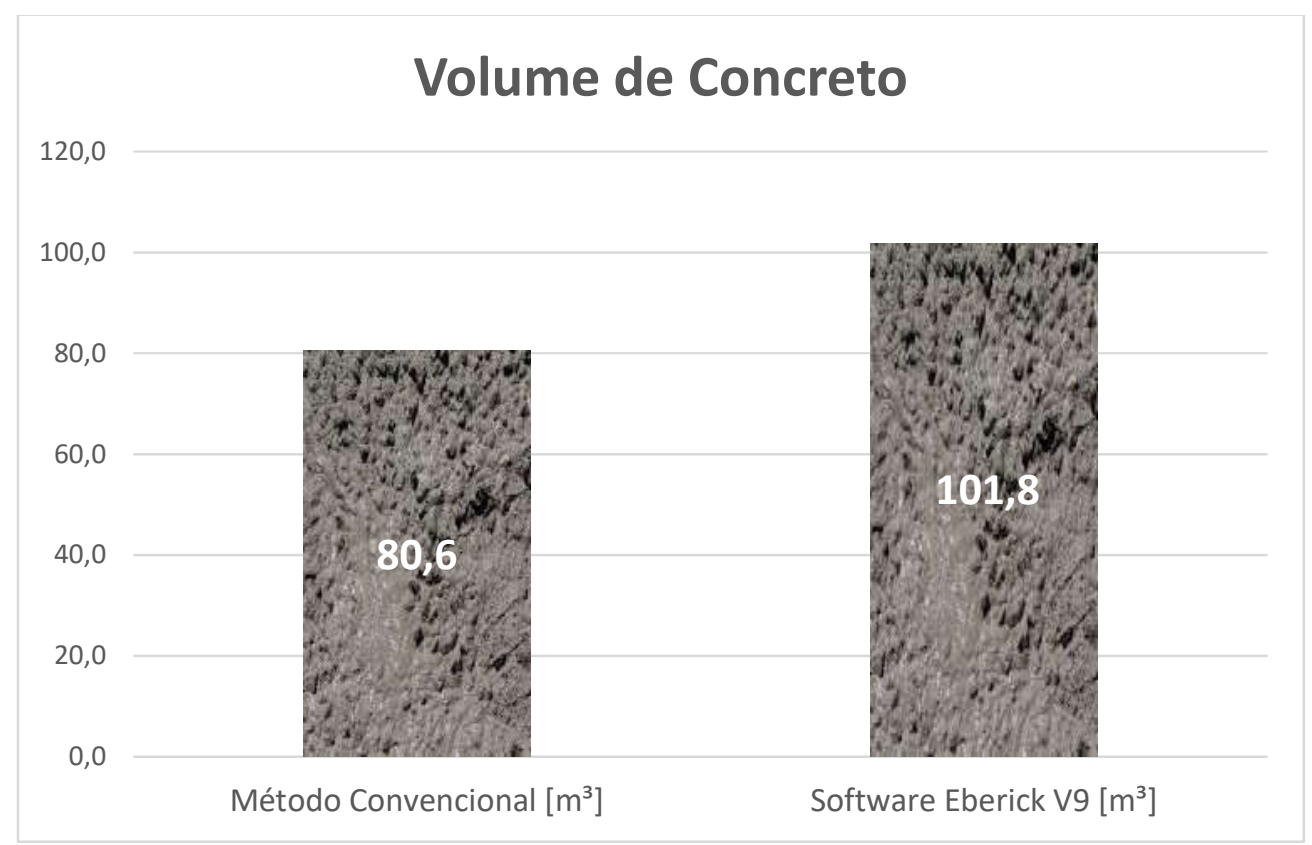

Gráfico (8) - Comparação Total de Concreto dos Pilares, Fonte: Autores (2016). 


\section{6 - CONCLUSÃO}

Conclui-se com os dados apresentados que de fato os programas de cálculo estrutural estão disponíveis para uma maior produtividade nos projetos estruturais. Porém nota-se que o uso de software de cálculo estrutural, exige do usuário um bom nível de conhecimento técnico, e normativo, que associado à experiência aumenta em muito as chances de sucesso na criação de um projeto estrutural racional e econômico. É importante que o usuário conheça muito bem a ferramenta que ele está utilizando, de maneira que em quando acusados erros pelos programas, o engenheiro saiba onde manipular no software para que haja uma correção no projeto. Em virtude de diferenças de análise e dimensionamento do software e no método de convencional, foi constatado que é possível fazer um dimensionamento mais econômico utilizando o Método Convencional, tendo uma redução de $41 \%$ no peso de aço e $11 \%$ no volume de concreto, entretanto com o Software Eberick V9 é possível elaborar um dimensionamento de uma forma mais rápida e mais criteriosa levando em consideração todas as prescrições normativas atuais e fatores que seriam inviáveis para o cálculo manualmente, com issodar-se ao software maior precisão e realismo de como a estrutura funcionará com as ações nela imposta. 


\section{7- REFERÊNCIAS}

ASSOCIAÇÃO BRASILEIRA DE NORMA TÊCNICA NBR 6123 Forças devidas ao vento em edificações. Rio de Janeiro, (1990)

ASSOCIAÇÃO BRASILIERA DE NORMAS TÉCNICAS. NBR 6118: Projeto de estruturas de concreto. Rio de Janeiro, (2003).

BASTOS $^{2}$, P. S. S. Fundamentos do concreto armado. Apostila. Departamento de Engenharia Civil, Faculdade de Engenharia de Bauru, Universidade Estadual Paulista - UNESP, Bauru, (2006, 98p).

CAUDURO, E. L. ; LEME, A. J. H. Aprotensão em edifícios sem vigas - Novas técnicasaumentam a qualidade e reduzem o custo total do edifício,(s/d., 14p.)

DEBS, A. L. H. C. Sistemas Estruturais. Material didático da disciplina SET177 Sistemas Estruturais II. São Carlos, Escola de Engenharia de São Carlos - USP, Departamento de Engenharia de Estruturas, 2007. Disponível em http://www.set.eesc.usp.br/cursos/SET177/ana/2-sistemas\%20estruturais.doc.

Acesso em (12/04/2016. 13p).

FIGUEIREDO FILHO, J. R. ; CARVALHO, R. C. Análise e comportamento de sistemasestruturais em concreto - Pavimentos de edifícios.Pós-Graduação em Construção Civil, São Carlos, Universidade Federal de São Carlos - UFSCar, Departamento de Engenharia Civil,( 2004, 34p.)

GIONGO, J. S. Concreto armado: projeto estrutural de edifícios. Apostila, São Carlos, Escola de Engenharia de São Carlos - USP, Departamento de Engenharia de Estruturas,( 2007, 184p).

JOST,Octavio.Curso de construção vol .IME instituto Militar de Engenharia, Rio de Janeiro, 1970 
LOURENÇO, P. J. B. B. Novas metodologias para o dimensionamento de betão armado. Escola de Engenharia, Universidade do Minho, (1992, 211p).

PINHEIRO, L. M. Fundamentos do concreto e projetos de edifício, São Carlos, SP,( 2007). Disponível em: <http://www.ufsm.br/>.

REBELLO, Y.C.P. A concepção estrutural e a arquitetura. S. Paulo, ZigurateEditora,( 2001, 271p).

ROCHA, Aderson Moreira da.Concreto Armado vol 2.23 ed Livrana Nobel São paulo 1990PINHEIRO, L. M. Fundamentos do concreto e projetos de edifício, São Carlos, SP, (2007). Disponível em: <http://www.ufsm.br/>.

LISERRE, Luiz.;RAMALHO,Marcio Antônio. Sistema computacional com geração de dados e visualização de resultados para estrutura de edifícios ( 2008, 59.p )

BARBOZA, Marcos Robiati. Concepção e analise de estruturas de edifícios em concreto armado,Bauru-SP, $\quad(2008 \quad$ ). Disponível emhttp://wwwp.feb.unesp.br/pbastos/concreto1/Rel.\%20Final\%20Marcos.pdf 
Anexo 1- Plantas

Anexo 1.1 - Planta de Arquitetura

Anexo 1.2 - Corte Esquemático do Projeto 
